\title{
CAMA
}

Centre for Applied Macroeconomic Analysis

\section{An Investigation of the Exchange Rate Pass- Through in the Baltic States}

\section{CAMA Working Paper 60/2019 August 2019}

Mariarosaria Comunale

Bank of Lithuania

Centre for Applied Macroeconomic Analysis, ANU

\section{Abstract}

In this paper, we investigate the Exchange Rate Pass-Through (ERPT) to import and consumer prices in the three Baltic states. We apply reduced form equations first. Then, to look at measures of shock-dependent ERPT, we use Bayesian VARs with zero and sign restrictions and a local projection exercise, using common euro area shocks. We find that results from reduced form equations are in line with the ERPT literature. As for shock-dependent ERPTs, the magnitudes are overall bigger than in the literature in the case of import prices. They get smaller for consumer prices and even smaller if we remove energy and food prices. 


\title{
Keywords
}

Exchange Rate Pass-Through, Baltic states, Shock dependence

\author{
JEL Classification
}

E31, F3, F41

Address for correspondence:

(E) cama.admin@anu.edu.au

ISSN 2206-0332

The Centre for Applied Macroeconomic Analysis in the Crawford School of Public Policy has been established to build strong links between professional macroeconomists. It provides a forum for quality macroeconomic research and discussion of policy issues between academia, government and the private sector.

The Crawford School of Public Policy is the Australian National University's public policy school, serving and influencing Australia, Asia and the Pacific through advanced policy research, graduate and executive education, and policy impact. 


\title{
An Investigation of the Exchange Rate Pass-Through in the Baltic
}

\section{States}

\author{
Mariarosaria Comunale \\ Bank of Lithuania* and $\mathrm{CAMA}^{\dagger}$
}

This version: August 2019

\begin{abstract}
In this paper, we investigate the Exchange Rate Pass-Through (ERPT) to import and consumer prices in the three Baltic states. We apply reduced form equations first. Then, to look at measures of shock-dependent ERPT, we use Bayesian VARs with zero and sign restrictions and a local projection exercise, using common euro area shocks. We find that results from reduced form equations are in line with the ERPT literature. As for shock-dependent ERPTs, the magnitudes are overall bigger than in the literature in the case of import prices. They get smaller for consumer prices and even smaller if we remove energy and food prices.
\end{abstract}

Keywords: Exchange Rate Pass-Through, Baltic states, Shock dependence.

JEL Codes: E31, F3, F41.

${ }^{*}$ Principal Economist. Applied Macroeconomic Research Division, Economics Department, Bank of Lithuania. Totoriu g. 4, LT-01121, Vilnius, Lithuania. E-mail: mcomunale@lb.lt

${ }^{\dagger}$ Research Associate, Centre for Applied Macroeconomic Analysis, The Australian National University, Canberra.

${ }^{\ddagger}$ The conclusions expressed in the paper are those of the author and do not necessarily represent the official views of the Bank of Lithuania, the ECB or of the ESCB. We would like to especially acknowledge the contribution of Andrejs Bessonovs (Latvijas Banka) and Dmitry Kulikov (Eesti Pank), who kindly shared the data and results for Latvia and Estonia for the reduced form equations and country-specific BVAR. We are very thankful to Ieva Rubene for sharing the codes and data for the reduced form, Justas Dainauskas for his help with the code on local projections. We also thank the ESCB joint WGF/WGEM Expert group on the Exchange rate pass-through for data and comments, Chiara Osbat, Konstantins Benkovskis, Karsten Staehr and the participants at the Bank of Lithuania research seminar for inputs and suggestions. This paper is partially based on Section 5 of ECB (2019). We thank Sara Tropper for language check and proofreading. 


\section{Introduction}

In the past few decades, the Baltic states have experienced several changes in their economies and, more specifically, in their relationships between exchange rates and inflation. Their strict fixed exchange rate regimes (for most of the period) led to their joining the euro area, which put a downward pressure on inflation that worked both directly and also via expectations of future inflation. Additionally, these small open economies are massively influenced by global factors - for example, they are highly dependent on energy imports - and European factors, as they are now part of the euro area; thus, for example, nominal exchange rates and policy interest rates are not decided at the national level. Thus, an updated analysis of the pass-through for the Baltics, considering both new data (covering transition, boom, crisis, recovery and low inflation/unconventional monetary policy) and new econometric techniques, is an important contribution for scholars, as well as for policy-makers.

Beirne and Bijsterbosch (2009) argue that ERPT estimates reported in previous research are highly sensitive to empirical methodologies and data periods, and that the wide variation in results may be due to factors that changed during the transition process. In the present paper, we claim that these differences may stem from the different shocks underlying the pass-through that impacted both prices and the exchange rate.

In this paper, we investigate the Exchange Rate Pass-Through (ERPT) in the three Baltic states, comparing the results from simple reduced form equations, still en vogue in the literature, to measures of shock-dependent ERPT and local projections using euro area shocks, which are common to all the members. These methods are not expected to deliver the same results and can be seen as different approaches to understanding the transmission of NEER variations to prices, based on different definitions. In light of the vigorous debate in the literature, our work addresses a central topic in the field. As no consensus exists concerning the ideal approach to ERPT estimations, we have decided to look at the whole spectrum to understand the link between NEER and prices in these countries and why we should be careful with plain, rule-of-thumb numbers. Each result can help us better grasp the transmission of exchange rates to prices in the Baltics. Our study may also be useful for analysing other small open economies in a monetary union or with fixed exchange rate regimes.

A handful of papers have explored the ERPT in Estonia, Latvia and/or Lithuania. None of these, however, investigated the possibility of prices and exchange rates reacting to the same shocks. In these papers, single-equations or VAR techniques are are generally used, and the exchange rate is not consid- 
ered as potentially driven by other shocks, as the prices are. The strong assumption that the exchange rate is governed solely by exogenous shocks to itself has already been challenged in some theoretical contributions (e.g. Corsetti and Dedola (2008)), but only recently applied in empirical measures of ERPTs aimed at having shock-dependent ERPTs (Shambaugh, (2008), Forbes et al. (2015; 2017; 2018), Comunale and Kunovac (2017) all using (B)VARs). Shambaugh (2008) suggests that the ERPT ratios to consumer inflation do not react to all shocks in the same way, and that demand shocks are of limited importance for pass-through. Import prices move in the same direction as the exchange rate after all shocks, excepting the shock in foreign prices.

Forbes et al. $(2015 ; 2017 ; 2018)$ confirms that the domestic monetary policy shock is associated with a large ERPT to consumer prices both in the UK and in a sample of advanced and emerging economies, with a much smaller pass-through found for domestic demand shocks. In this setup, the ERPTs are not constant over time - they depend on the composition of economic shocks governing the exchange rate. The time-varying ERPT is here indeed obtained as ratios between cumulated IRFs of prices and those of exchange rates following a particular shock weighted by the importance of the same shock in the historical decomposition of the exchange rate. Lastly, Comunale and Kunovac (2017) analyse the euro area and 4 major economies, and find that pass-through is strongest when the exchange rate movement is triggered by (relative) monetary policy shocks and exchange rate shocks.

There are many reasons for the shock-dependence of ERPT. For example, price setters may react differently to exchange rate movements triggered by different economic shocks. Alternatively, when the exchange rate is predominantly determined by demand shocks that presumably appreciate the exchange rate, ERPT estimates may be of the wrong sign. Demand shocks may appreciate the exchange rate but also raise inflation, and the sign of the correlation between exchange rates and prices will be the opposite of the expected one. Thus, the ERPT may in fact depend on the shock that triggers exchange rate movements - a feature often overlooked in the empirical analyses of ERPT.

In this paper, we will apply a Structural Bayesian VAR (BVAR) a la Comunale and Kunovac (2017) in order to investigate the ERPT in the Baltic states and how it depends on the identified shocks. We compare these results to very simple reduced form setups, i.e. single-equation frameworks also taken from the Phillips curve. Then, we draw a comparison between such results, from single equations and full country-specific BVARs, and those from a linear projection exercise. This is done by using common euro area shocks taken from the BVAR literature. Our rationale is that the modelling challenges of analysing the shock dependence of the impact of exchange rate changes increase when looking at 
individual countries: Structural VARs exchange rate and monetary policy shocks, which are mostly common to the whole euro area and not entirely country-specific in the considered time span, cannot be fully identified using data from only one country. For instance, even if the NEER is country-specific, due to the initial sample periods and differences in trade partners, it is for the most part linked to the behaviour of the euro. For many years, Estonia and Lithuania had intermediate regimes linked to the US dollar (Lithuania) and the euro afterwards (Estonia). Lithuania moved to a peg to the euro in 2002, while Estonia shifted from the German Mark to the euro already in 1999. The only exception seems to be Latvia, which had a fixed regime to Special Drawing Rights (SDR) until 2005. All these countries were in the ERM II before joining the euro zone. ${ }^{1}$ For relative monetary policy, the reasoning is similar and the variable is now only driven by decisions at the euro area level. As such, we later provide a local projection exercise, with common euro area shocks identified in euro area-specific Structural BVARs and then extrapolated and used as regressors.

Capturing the ERPT is never trivial, and this is even more so in the case of consumer prices. We find that our results from reduced form equations are in line with the literature. In contrast, our results from country-specific BVARs and local projections differ from those found in the literature. It is important to remember, though, that these methods are not expected to deliver the same results with respect to the reduced form equation, and that they are based on different definitions. The magnitudes for common euro area exchange rate shocks in the local projections are generally bigger than in the literature in the long run for import prices (between 0.5 in the case of Estonia and Lithuania, and 0.8 in the case of Latvia). For consumer prices the magnitude is smaller, i.e. around 0.1 in the short run and 0.2 after four quarters. Looking at the pass-throughs we found that, by applying several methods, Latvia seems to be an outlier most of the time. Lastly, the results for core HICP are smaller both in the cases of exchange rate shock and relative monetary policy shock, which highlights the importance of the pass-through of energy and food prices in these economies. This is confirmed by the non-energy industrial prices results, which are mostly zero in the case of exchange rate shocks. Only in Estonia and in Lithuania can we see some influence of monetary policy shocks on the prices of services.

In Section 2, we describe briefly the literature and results on the ERPT, placing particular focus on the Baltic states; then, Section 3 clarifies the different definitions used in this paper. Section 4 describes the data, Section 5 looks at the econometric setups in greater detail: reduced form equations, BVARs

\footnotetext{
${ }^{1}$ To become a member of the euro area, the exchange rate must have been linked to the euro through membership of the exchange rate mechanism ERM II for at least two years.
} 
and local projections, as well as a list of the data and sources. Section 6 provides the results with different methods, and Section 7 concludes.

\section{Literature review on ERPT in the Baltic states}

Only a few papers cover the link between inflation dynamics and exchange rates, or more explicitly, the ERPT in Estonia, Latvia and Lithuania. As reported in Beirne and Bijsterbosch (2009), the ERPT estimates from previous studies would suggest a high degree of sensitivity of results to selected empirical methodologies and data periods; the wide range of results may be due to factors that changed during the transition process (see below Bitans, 2004 and Masso and Staehr, 2005, compared to Lopez-Villavicencio and Mignon, 2016). ${ }^{2}$ We argue here that the differences might have originated from the different shocks underlying pass-through that impacted both prices and exchange rates.

Masso and Staehr (2005) look at inflation dynamics and linkages to nominal adjustments in the Baltic states, estimating Phillips curves for the immediate transition period. They find that consumer price inflation in the Baltics was strongly influenced by changes in the real exchange rates before joining the EU in 2004. In their very fixed exchange rate regimes, the resulting downward pressure to inflation worked both directly and via expectations to future inflation, making the ERPT larger. In a more recent contribution, Lopez-Villavicencio and Mignon (2016) explore the transmission of NEER shocks to prices in emerging economies that adopted inflation-targeting regimes for a longer time span: between January 1994 and July 2015 (including small EU countries like Czech Republic, Hungary, Poland, Romania and Slovakia). ${ }^{3}$ They rely here on a general single-equation specification, as in Goldberg and Knetter (1997). The authors analyse the ERPT issue, and then focus in a more dynamic way on their specific inflation environment, namely, monetary policy and domestic institutional factors. In economies that adopted inflation targeting (or a fixed and credible exchange rate regime), the exchange rate shocks have been quickly incorporated into expectations and then into prices. Hence, a recent decline in ERPT could be linked to an improved inflation environment over time, as also found in Saiki (2011). In the latter study, the author also shows that monetary integration affects the ERPT, which seems to be converging to the euro area average.

\footnotetext{
${ }^{2}$ The authors provide also a table comparing the results in the literature covering new member states up to 2009.

${ }^{3}$ For a complete literature review on earlier estimates of ERPT to CPI in emerging economies, see Comunale and Simola (2018). The estimates for the ERPT to CPI (due to 0.01 change in NEER or bilateral rate with USD) range from 0.05 and 0.22 after $1 \mathrm{Q}$ and from 0.06 and 0.91 after $4 \mathrm{Q}$.
} 
Bitans (2004) is the first paper to explicitly cover the ERPT for all three Baltic countries. ${ }^{4}$ The author uses a recursive VAR (vector autoregression) with Cholesky identification for the pre-EU period. Bitans (2004) finds ERPT to consumer prices at impact being 0.21 for Estonia, 0.13 for Latvia and 0.22 for Lithuania. After 1 year, it goes up to 0.34, 0.26 and 0.28 respectively. ${ }^{5}$ In general, Bitans (2004) finds that countries with fixed/rigid intermediate exchange rate regimes, such as the Baltic states, appear to have a higher ERPT compared with countries with at least some exchange rate flexibility (e.g. the Czech Republic, Hungary), confirming Masso and Staehr's (2005) main outcomes. Dabusinskas (2003) analyses only the Estonian case for the pass-through to import, producer and consumer prices, both in total and disaggregated. He finds that, in aggregate, the long run pass-through to import and producer prices are between 0.4 and 0.5 , though the precision of these estimates is low. In contrast, no significant ERPT is estimated to consumer prices.

Maria-Dolores (2009) estimates the ERPT into the prices of imports (several industries are covered) and consumer prices that originated inside the euro area for some new EU member states, including Latvia. The author applies single equation methods (with and without Error Correction Models). The author finds that ERPT is incomplete in the short run for all the countries in import prices but in Latvia the elasticity is next to one (0.9 in the short run). In the long run, ERPT is slightly smaller (0.76). Latvia has one of the largest values also in the case of ERPT to consumer prices (between 0.24 and 0.36, depending on the openness variable used). In general, new member states have larger ERPTs than the euro area (based on data up to 2006). There is also a larger response to changes in exchange rates in the service sector as compared to manufacturing.

Beirne and Bijsterbosch (2009) also look at nine new member states, including the three Baltic countries. The ERPT analysis is conducted by applying a five-variate cointegrated VAR for each country and impulse responses derived from the VECM (vector error correction model). The authors find notable differences depending on the exchange rate regimes, confirming the main findings in the previous studies. There are also differences across Baltic states. Latvia has a greater ERPT after 2Q (0.35) compared to the other two countries ( 0.06 for Estonia and 0.15 for Lithuania). In the long run, only Lithuania is far from having a complete pass-through. ${ }^{6}$ Jimborean (2013) also covers these three countries (together with other new member states) with data from 1996Q1 to 2010Q2 in both a dynamic panel and a

\footnotetext{
${ }^{4}$ The exchange rate in this strand is always a sort of Nominal Effective Exchange Rate (NEER).

${ }^{5}$ If we look at the period 1993-1997, the ERPTs are much larger in the three countries. For HICP in Lithuania, the pass-through is even complete after 2 years.

${ }^{6}$ Their model implicitly assumes that there is full exchange rate pass-through to import prices (as also in Bitans, 2004).
} 
country-by-country equation. The estimated ERPT to consumer prices is statistically significant only in Estonia.

More recent estimates can be found in Carriere-Swallow et al. (2016), who look at a wider sample of 31 advanced (including the Baltic states) and 31 emerging market economies from January 2000 to December 2015. They employ a reduced-form specification (see Campa and Goldberg, 2005; Gopinath, 2015) and then estimate cumulative responses in a panel setting using local projections, as in Jorda (2005). The ERPT to consumer prices is 0.48 in Estonia after 12 months and 0.22 after 24 months; for Latvia the elasticities are 0.26 and 0.68 respectively, and for Lithuania 0.39 and $0.64 .^{7}$ Summing up, using more recent data, the ERPT to consumer prices in the Baltics does not seem to have declined, as suggested in the literature. As Beirne and Bijsterbosch (2009) note, this conclusion should be approached cautiously, given the very different econometric methods applied, the very wide range of estimated passthroughs and the relative limited number of studies on these countries.

For readers' convenience, we now show the different magnitudes found in the literature for the ERPT to import and consumer prices (in aggregates) in Estonia, Latvia and Lithuania, in the short and long run.

[Insert here Table 1]

\section{Definitions of pass-through}

This section aims to clarify the differences between the widely used definition of ERPT and the new, shock-dependent ERPT (see also ECB, 2019). These are not expected to deliver the same results and can be seen as different approaches to understanding the trasmission of NEER variations to prices.

The largest branch of this literature focuses on a "structural" definition of ERPT arising from a pricing equation, in which the considered price index (or its growth rate) is regressed on the exchange rate and some control variables. Both in empirical single-dynamic equations and in VARs, exchange rate pass-through at any given horizon is defined as the impulse response of inflation to the exchange rate "shock". In single equations, this "shock" is not structurally identified but assumed to be exogenous by taking care not to have relevant omitted variables in the regression; in VARs, it is identified using various schemes. Following ECB (2019), we look at a simple pricing equation, in which the considered

\footnotetext{
${ }^{7}$ The elasticities represent the cumulative responses of headline consumer prices to a 1-percent innovation in the nominal effective exchange rate.
} 
price index (or better, its growth rate) is regressed on the exchange rate and some control variables. In macroeconomic studies, the impact of exchange rate changes on the aggregate inflation is investigated by using a distributed lag equation, as below:

$$
\Delta p_{t}^{z}=\alpha+\sum_{k=0}^{K} \beta_{k} \Delta s_{t-k}+\sum_{k=0}^{K_{r}} \sum_{r=1}^{R} \gamma x_{r t-k}+\varepsilon_{t} \text { with } z \in(F, H, C)
$$

where $s_{t}$ is the exchange rate (nominal effective or bilateral; in this paper, we only consider NEER). The $x_{r t}$ are $\mathrm{R}$ control variables, which normally include lags of $\Delta p_{t}^{z}$ giving rise to auto-regressive distributed lag, ARDL, specifications. $\mathrm{K}$ is the maximum lag length. This applies to any aggregate price: import, producer, consumer, etc. The exchange rate pass-through at any horizon $\mathrm{h}$ can be measured by the (cumulative sum of) the coefficients of the exchange rate: ${ }^{8}$

$$
\operatorname{ERPT}_{h}^{z}=\sum_{k=0}^{h} \beta_{k} \text { where } z \in(F, H, C)
$$

The new, shock-dependent ERPT, which is also called the Price-to-Exchange-Rate Ratio (PERR), as in ECB (2019), is instead seen not as "transmission" of exchange rate changes, but as "co-movement" of prices and exchange rates given different shocks, as:

$$
\operatorname{PERR}_{j, h}^{z}=\frac{\sum_{t=1}^{h} \operatorname{IRF} F_{j}\left(\Delta p_{t}^{z}\right)}{\sum_{t=1}^{h} \operatorname{IRF} F_{j}\left(\Delta s_{t}^{z}\right)} \text { where } z \in(F, H, C)
$$

This measure reflects the correlation between the exchange rate and inflation conditional on each of the identified shocks serving as a shock-dependent ERPT measure/PERR. We take the ratios of the cumulative sum of net changes of the IRFs of inflation to each of the shocks over the cumulative sum of net changes of the IRFs of exchange rate changes (q-o-q) to the same shock. Here, all shocks are inflationary, and an increase means appreciation. The exchange rate is always the Nominal Effective Exchange Rate (NEER).

Both the ERPT and the PERR measures are useful for assessing the relationship between exchange rates and prices, and these two measures are complementary. The "rule of thumb" from reduced form estimations in a macroeconomic setup can be of some guidance only in the case of import prices, where this comes from pricing equations. As for consumer prices, this is less clear due to the process of price

\footnotetext{
${ }^{8}$ If we want to have a measure of ERPT in a longer horizon and we do not have enough lags h, a possible way is computing it as in Jimborean (2013): $\frac{\sum_{k=0}^{K} \beta_{k}}{1-\sum_{k=0}^{K_{r}} \gamma_{k}}$, i.e. the ratio of the cumulative $\beta_{k}$ over one minus the cumulative coefficients of inflation lags.
} 
aggregation. In a nutshell, a simple ERPT may be informative for import prices, while a more shockdependent pass-through can be considered for HICP and its components. This approach, however, is far from straightforward; it is very hard to find a robust characterisation across models of the configuration of shocks that drive the exchange rates and prices at any given point in time, and this is especially true for one country. Given that, we additionally provide a local projection exercise by using identified common shocks to the euro area (monetary policy and exogenous exchange rate shocks), looking at how consumer prices and components react.

\section{Data description}

For the calculation of ERPT and PERR, we make use of the following set of variables: real GDP (seasonally and working-day adjusted), HICP (seasonally and working-day adjusted), country-specific competitor export prices weighted by country's import shares, total import deflator: extra plus intra EA for goods and services, and extra EA country-specific broad Nominal Effective Exchange Rates (NEER). For the reduced form estimations and local projections, we also use the HICP components (core HICP, non-energy industrial goods price index, NEIG and services price index, SERV). ${ }^{9}$ These series are retrieved from ECB SDW or ECB internal sources (ECB projections database), and they are seasonally adjusted. For the reduced form, the inflation expectations of Lithuania are proxied the current year and next year expectations from Consensus Economics, while no expectation variables are used in the cases of Estonia and Latvia. As for the interest rates, we used the shadow rates for the euro area and the US from Krippner (2016). All the variables, except the interest rates, are in q-o-q log differences. The data covers the period from 1999Q1 to 2017Q4 at quarterly frequency. ${ }^{10}$

\section{Econometric setups}

\subsection{Reduced form equations}

We start by looking at a bivariate relation using the change in the inflation rates as a function only of the change in the exchange rate, reflecting a simple correlation analysis. ${ }^{11}$ In equation (2), a very

\footnotetext{
${ }^{9}$ The analysis in this paper is based on inflation series for the euro area before the package holiday methodological change.

${ }^{10}$ The data are until $2017 \mathrm{Q} 3$ for the reduced form estimations.

${ }^{11}$ See Riksbank, "The impact of the exchange rate on inflation" in Monetary Policy Report, December 2016. The code, kindly shared by Ieva Rubene, was developed starting from the code provided by Riksbank.
} 
general representation is shown (variables in log changes). This come directly from equation (1) above, where some country-specific time dummies are also added.

$$
\Delta p_{t}=\alpha+\sum_{i=1}^{R} \gamma_{i} \Delta p_{t-k}+\sum_{i=0}^{K} \beta_{i} \Delta s_{t-i}+\delta_{i} \text { dummies }+\varepsilon_{t}
$$

Next, a Phillips-curve-type of specification is introduced, where the exchange rate impact was analysed in two ways: a two-step and a direct approach. Different dummies as compared to the previous method are applied only in Latvia.

In step one of the two-step approach, changes in total (intra-EA and extra-EA) import prices (ip) are estimated as a function of the changes in the exchange rate (NEER) and / or changes in the competitor export prices in national currency $(c x d)$. This is basically the equation above, which includes competitor export prices among the regressors. Then, in step two, the (annualised) inflation rate is made dependent on an autoregressive term, changes in import prices and a measure of slack in the economy, inflation expectations, and the time dummies. Thereafter, two forecasts are produced, with the import prices over forecast horizon equal to the two respective forecasts of import prices obtained in the first step, while all other variables are set at the value of their last observation. In the direct approach, the exchange rate was included as regressor in the Phillips-curve equation. ${ }^{12}$

The dummy for Estonia and Lithuania refers, in general, to the global financial crisis (Dummy=1 in 2009Q1). For Latvia, the dummy is equal to one if we are in three different quarters: 2008Q4, 2009Q1 or 2015Q3. In the Estonian case, the number of lags are automatically selected for the bivariate equation and nowcast (it is one in both cases). For the Phillips curve, the augmentation is set to 3 lags for exchange rates, imports and oil prices, and to 1 lag for the inflation and output gap. For Latvia and Lithuania, the number of lags is set to either zero or one for the NEER in the bivariate equation to HICP or core HICP. Three lags are used in the Phillips curve for Lithuania. The differences in lags and dummies stem from correcting the general setup in equation (2) to the specific characteristics of the three countries. ${ }^{13}$

\subsection{Bayesian VAR}

In order to investigate how the ERPT depends on the composition of economic shocks hitting our countries of interest, here we identify a full set of economic shocks from a six-variable BVAR. For each

\footnotetext{
${ }^{12}$ Please see Riksbank (2016) for more details on the abovementioned steps and procedures.

${ }^{13}$ We are very thankful to Andrejs Bessonovs and Dmitry Kulikov for sharing their setups and results.
} 
of the six shocks, the pass-through is computed as the ratio between the cumulated impulse response function of inflation and of the exchange rate (NEER), following that particular shock, as explained in Section 3. Our identification comes from Comunale and Kunovac (2017), and we apply block exogeneity in order to prevent foreign variables from being influenced by changes in our countries. We identify a full set of shocks by imposing a combination of sign restrictions and zero (short- and long-run) restrictions. ${ }^{14}$ The full set of identified economic shocks includes: domestic aggregate supply shock; domestic aggregate demand shock; foreign supply shock; foreign demand shock; an exogenous exchange rate shock and a relative monetary policy shock. The latter emerges from the difference between the shadow rates in the euro area and and those in the US. The identification is summarised in the table below (Table 2).

The fact that the ERPT depends on the shock that triggers the exchange rate movement suggests that the overall magnitude of pass-through varies with the particular composition of economic shocks governing exchange rate dynamics. In order to assess the relative importance of individual shocks for overall pass-through to inflation, we rely on a historical decomposition of the NEER resulting from our identified BVAR (Figure 1 in the Appendix). A measure of time-varying (TV) ERPT is then calculated as a linear combination of individual pass-through ratios over all shocks, weighted by the relative importance of that shock in the historical decomposition of the exchange rate, as shown below:

$$
\operatorname{ERPT}_{t}^{j}=\sum_{k=0}^{K} \theta_{k}(1) \widetilde{y_{j, t}^{k}}
$$

$\theta_{k}(1)$ denoting the ERPT ratios at 1-year horizon and $\widetilde{y_{j, t}^{k}}$ is the relative contribution of the $k$ th structural shock to the $j$ th variable at period $t$. The ERPT measure calculated in this way is shockdependent, and in that sense it is also time-varying by construction.

The modelling challenges of analysing the shock dependence of the impact of exchange rate changes increase, however, when looking at individual countries: Structural BVARs exchange rate and monetary policy shocks, which are mostly common to the whole euro area and are not entirely country-specific in the time span under study, cannot be identified using data from one country only. This is why we also provide a local projection exercise (see next sub-section), with common euro area shocks identified in a euro area-specific Structural BVAR and then extrapolated and used as a regressors.

[Insert here Table 2]

\footnotetext{
${ }^{14}$ For more detail, see Comunale and Kunovac (2017).
} 


\subsection{Local projections}

We want to assess how HICP, its components (including HICPX, i.e. core HICP) and import prices react to EA common shocks identified via BVARs, i.e. exchange rate shock or monetary policy shock (see also Comunale, 2019 for results for the euro area). In this case, we used several common shocks from this strand of literature (see ECB, 2019). In order to do so, we make use of a local projection exercise following Jorda (2005). Recently, Coibion, Gorodnichenko and Ulate (2018) used a similar idea for potential output and demand/supply shocks, and Gorodnichenko and Lee (2017) used it for TFP shocks and monetary policy shocks. Leiva-Leon et al. (2018) make use of it for ERPTs in the euro area in a time-varying dynamic factor model. In the local projections, the shocks are directly used, not the original series (shadow rates or NEER in our case). This is because we are interested in the dynamic responses of inflation and GDP growth to structural shocks, previously identified. As Gorodnichenko and Lee (2017) point out, this is normally done by using SVARs or DSGEs to construct the responses. However, focusing on single shocks and and single-equation methods to compute them, as in the local projections, helps when the structural shocks cannot be well-identified. Moreover, it allows other sources of variation to be unspecified and imposes no restrictions on the shape of the impulse responses.

In our baseline, the shocks and dependent variables appear without any lags, and we do not include any further controls. This setup is applied on HICP (and components) regressed on a constant and a shock. A check by using simple regressions and multiple shocks and lags (from 0 to 4 quarters) is also provided for robustness.

In this local projection framework, more specifically, we have different inflation measures (y-o-y changes) as the dependent variable for each Baltic state: $Y_{t}$. In the regressors set, we add the outcomes from common FX and monetary policy shocks $\epsilon_{t, k}$. The common monetary policy shocks can be of different types, depending on which BVAR we consider. We can have only a euro area monetary policy shock (following Forbes et al. (2018)), both a euro area and a US monetary policy shock, as in the Montes-Galdon et al. (2019) approach and then a relative monetary policy shock a la Comunale and Kunovac (2017) or as in Leiva-Leon et al. (2018). The shocks are taken in q-o-q variations; hence, the possible changes in exchange rates and monetary policy in a quarter can play a role in determining the inflation rate $\mathrm{y}-\mathrm{o}-\mathrm{y}$.

$$
Y_{t}=\alpha+\phi_{k} \epsilon_{t, k}+\varepsilon_{t}
$$


In the formula above, $k$ refers to the shock (to exchange rate or monetary policy). The different $\phi_{k}$ coefficients will thus be country-specific.

\section{Results}

\subsection{Reduced form ERPT}

For each country, we show the change in the level of consumer prices, HICP, or HICP excluding food and energy (HICPX), following a 10\% (0.01) change in NEER for the two considered reduced-form specifications (bivariate and Phillips curve). The left-hand-side figures are for headline HICP, and the right-hand-side ones for HICP excluding food and energy, HICPX. The comparison across models for headline HICP is also reported in Table A1 in the Appendix. ${ }^{15}$

In the case of Latvia, NEER appears to be a statistically significant variable explaining inflation developments. A Phillips curve-type regression indicates that the long-run impact of the unexpected increase (shock) of NEER on headline HICP, on average, is estimated to be 0.37 , but the long-run impact on HICPX (exlc. food and energy) is much lower. The latter is, on average, about 0.04. The impact of NEER to HICP or HICPX changes is not significantly different from zero in the bivariate regressions.

For Lithuania in the bivariate approach, the results for HICP are much bigger than the those in the Phillips curve exercise. The outcomes for HICPX seems to be more correct in magnitude. The passthroughs are bigger with respect to the aggregate EA, converging to 0.06, but still very much smaller as compared to HICP. As for the Phillips curve: HICPX experiences the most plausible outcomes once again. ${ }^{16}$ These differences in ERPT between HICP and HICPX may be due to the importance of energy and commodities imports and prices in the HICP both in the case of Lithuania and Latvia. This does not seem to be the case, however, for Estonia. For the latter, the results from the reduced form equations for HICP are much smaller than in Latvia and Lithuania, as also reported in the literature. As for HICPX, the pass-through is not very different from the HICP one.

[Insert here Fig. 1-3]

\footnotetext{
${ }^{15}$ Results for NEIG and services are available on request. No results for import prices are available.

${ }^{16}$ The latter works also in the case of the nowcasting approach (i.e. if we apply monthly data instead of quarterly).
} 


\subsection{Shock dependent ERPT/PERR}

In the case of Estonia, the baseline BVAR with block exogeneity is applied. For Latvia, various alternative identification schemes are tested, bringing the results closer to a small open economy. Moreover, the assumption on the demand shock having no restriction on interest rate and exchange rate is relaxed. It seems, however, that the results of ERPT to import prices are subject to additional validation, as a profile of IRF is not as expected - instantaneous impact is very high, which leads to a gradual decrease. There are similar results when specific setups are applied. ${ }^{17}$

For Lithuania, own short-term rates before joining the euro area are applied with no impact of domestic variables on interest rates and the exogenous exchange rate. As for Latvia, in the case of PERR to relative monetary policy to prices, some instantaneous impacts are very high, which leads to a quick decrease. This is especially the case for exogenous exchange rate shocks. This is the only country in which the PERRs are significantly different from zero.

Given the overall consensus, also found in the literature, that the most relevant PERRs are those related to monetary policy or exogenous exchange rate shocks, we reported the relative results for our countries below (Fig. 4-6). ${ }^{18}$ It is difficult, however, to find any significant results for Estonia and Latvia. In terms of magnitude, in Estonia the PERR to HICP following an exogenous exchange rate shock it is around 0.2-0.4, while after a relative monetary policy shock is around 0.2. In the case of import prices, the numbers are only slightly bigger. For Latvia, we have much larger PERR to HICP in the case of a relative monetary policy shock, while it is around 0.5 for an exogenous exchange rate shock. Surprisingly, these results are reversed if we look at import price PERRs, where the largest is in the case of an exogenous exchange rate shock. Ultimately, the Lithuanian results point to very similar results compared to the Estonian ones in terms of PERR to HICP and import prices (i.e. between 0.2 and 0.6$).^{19}$

[Insert here Fig. 4-6]

A measure of time-varying (TV) ERPT is then calculated as a linear combination of individual PERRs over all shocks, weighted by the relative importance of that shock in the historical decomposition of the exchange rate (for the NEER historical decomposition for each country, see Fig. A1 in the Appendix).

\footnotetext{
${ }^{17}$ We are very thankful to Andrejs Bessonovs and Dmitry Kulikov for sharing their setups and results.

${ }^{18}$ The full set of results by using the other shocks is available on request.

${ }^{19}$ The relatively flat IRFs may depend on how the shocks are identified and restrictions are imposed (the zero-sign restrictions are imposed in the short run and in the long run we have some zeros restrictions; see Table 2).
} 
Summing all the PERRs, either significant or non-significant, we do not see any measure of TV-PERR which is significantly different from zero (see Fig. 7-9). Taking instead the average of the last year available, i.e. 2017, the TV-PERR for the countries lies between 0.17 (Latvia) and 0.06 (Lithuania). ${ }^{20}$ This is somewhat in line with recent TV estimates of the simple ERPT from ECB (2019) and Dainauskas and Quittner (2019), where the pass-through for Latvia is the biggest as well in recent years. For import prices, the TV-PERR recently reached 0.16 in Estonia (being lower before the crisis) and 0.10 in Lithuania, while much higher in Latvia (0.43). On average, in 2017, the Latvian TV-PERR was about 0.38 , again the highest across the three countries.

It is worth bearing in mind that there is a huge modelling challenge in analysing shock dependence in a country-specific setup, and this can be the main driver of the insignificant results we got from the PERR analysis. Structural VARs exchange rate and monetary policy shocks, which are mostly common to the whole euro area and not entirely country-specific in the considered time span, cannot be fully identified using data from only one country. For instance, even if the NEER is country-specific, due to the initial sample periods and differences in trade partners, it is for the most part linked to the behaviour of the euro. For many years, Estonia and Lithuania had intermediate regimes linked to the German Mark/euro afterwards (Estonia) or the US dollar/euro afterwards (Lithuania). Lithuania moved to a peg to the euro in 2002, while Estonia shifted from the German Mark to the euro already in 1999. The only exception seems to have been Latvia, which had a fixed regime to Special Drawing Rights (SDR) until 2005. ${ }^{212223}$ This different regime is also evident in the NEER historical decomposition (see the Appendix). At some point, however, the three countries joined the ERM II, as a prerequisite to joining the euro zone. For relative monetary policy, the reasoning is similar and the variable is now only driven by decisions at the euro area level. This is why we also provide a local projection exercise, with common euro area shocks identified instead in a euro area-specific Bayesian SVAR, and then extrapolated and used as a regressors.

[Insert here Fig. 7-9]

\footnotetext{
${ }^{20}$ If we consider only the median over the entire period considered, the TV-PERR to HICP in Estonia is less than 0.2 , in Latvia it is very close to zero and Lithuania stays in between.

21 "Special Drawing Rights" (SDR) is an accounting unit devised by the IMF. In the 90s, it consisted of a weighted average of the currencies of the United States, Germany, France, Japan and the UK.

${ }^{22}$ For more details on the history of exchange rate regimes in the Baltics, see Staehr (2016).

${ }^{23} \mathrm{We}$ also performed a check with data for Latvia from 2005 only with local projections. The results do not change considerably compared to our baseline for the PERR to FX shock and the magnitude is just slightly bigger in the case of relative monetary policy shock. In any case, the results are not significantly different from zero for consumer prices.
} 


\subsection{Linear projection exercise}

For local projections, we report the average $95 \%$ confidence intervals across the same (common) shocks coming from the selected euro-area BVARs. We look at 1) exchange rate shocks, from NEER (as in the identification a la Forbes et al., 2018 or Comunale and Kunovac, 2017) or bilateral EURUSD (as in Leiva-Leon et al., 2018 or Montes-Galdon et al., 2019, and 2) relative monetary policy shocks (as in Comunale and Kunovac, 2017 and Leiva-Leon et al., 2018). The results for the three Baltic states for HICP and HICPX are reported in Fig. 10-12 in case of 1) exchange rate shocks and 2) relative monetary policy shocks. ${ }^{24}$

[Insert here Fig. 10-12]

For 1) exchange rate shocks, their impact on HICP and HICPX is mostly non-significant at any horizon considered. For relative monetary policy shocks, we have some positive and significant response for Estonia in HICP and HICPX (in the short run) and in Lithuania for HICP in the short run. By using common euro area FX shocks (i.e. shocks to NEER), it is very difficult to find any significant PERR to consumer prices. Overall, the results for core HICP are smaller than those for HICP, both in the case of FX shocks and of relative monetary policy, which highlights the importance of the pass-through of energy and food prices in these economies.

We repeated the same exercise for import prices, finding more significant responses to common shocks. Like for Estonia, the coefficient for a shock in NEER is of around 0.5 after 4 quarters and significant indeed up to that point. The response to the relative monetary policy shock is similar in magnitude and within the $95 \%$ confidence bands. After 3 years, this coefficient reaches one. In Latvia, the response of import prices to an exchange rate shock is borderline significant and already quantified at 0.5 after 1 quarter and 0.85 after 1 year. For relative monetary policy shocks, the value is 0.7 after $1 \mathrm{Q}$ and above 1 after 1 year. The magnitudes are very similar in Lithuania, but for FX shocks it is trickier to find significant values.

We also performed a check with data for from 2005 only, to look at possible different outcomes given the specificity of the Latvian case (see section above). The results do not change meaningfully compared to our baseline for the PERR to NEER shocks, and the magnitude is just slightly bigger in case of

\footnotetext{
${ }^{24}$ The results with euro area and US monetary policy shocks are available on request. These will be based on only on Montes-Galdon et al. (2019) for the latter, while the former is an average of shocks from Montes-Galdon et al. (2019) and an identification a la Forbes et al. (2018).
} 
a relative monetary policy shock. In any case, the results are not significantly different from zero for consumer prices.

[Insert here Fig. 13-15]

Lastly, we look at some price's components, such as price of services (SERV) and non-energy industrial goods (NEIG). ${ }^{25}$ In Estonia, the biggest and most significant results are for relative monetary policy shocks in the case of non-energy industrial goods and the price of services, which reach 0.32 after one year and a half and 0.8 at the end of the 3rd year. The responses are much smaller than for the HICP until the 4th quarter. For Latvian NEIGs and price of services, by contrast, we do not find any significant result. ${ }^{26}$ The Lithuanian results are somewhere in between. We see no significant responses for nonenergy industrial goods, or for FX shocks for service prices. For the latter, the responses to common relative monetary policy shocks are borderline significant at $95 \%$ confidence and of around 0.5 after one year and one after 3 years.

The exercise was also done running simple regressions with monetary policy and exchange rate shocks added together, as they are orthogonal by construction, or separately, as in the local projections, with included lags from 0 to 4 . The results with common shocks together or separated are very similar, and these are comparable to those reported from local projections (see Comunale, 2019 for the full set of results for the euro area countries).

\subsection{Summary of results from our models}

We summarize in Table 4 the ERPT/PERRs we found for the country-specific BVARs and local projections for both import prices and consumer prices (for the latter, the results for each reduced form equations are in Table 3). We report here only the outcomes after 1 quarter and 4 quarters. ${ }^{27}$ These methods are not expected to deliver the same results and can be seen as different approaches to understanding the transmission of NEER variations to prices, based on different definitions (see Section $3)$.

In general, the magnitudes we got from this simple reduced form exercise are not too different from the those found in previous studies (see Table 3). Nonetheless, this does not imply that this is the right way to proceed. Capturing ERPT is never a trivial exercise, and this is particularly true in the case of

\footnotetext{
${ }^{25}$ The complete set of results for NEIG and SERV is available on request.

${ }^{26}$ The magnitudes are smaller than for the HICP at every horizon for NEIG and very large for SERV.

${ }^{27}$ The complete set of results up to 12 quarters or 24 quarters, depending on the model, is available on request.
} 
consumer prices. Indeed, for consumer prices, a simple ERPT is unclear due to the process of prices aggregation. For import prices, however, it can be of some guidance, coming from pricing equations.

We thus looked at the shock dependent ERPT/PERR by using a country-specific BVAR (Table 4), following a recent strand of literature introduced by Shambaugh (2008), Forbes et al. (2015; 2018) and Comunale and Kunovac (2017). The latter paper also suggested the "recombining" of shock-dependent impacts using as weights the importance of each shock in the historical decomposition of the exchange rate. This approach, however, is far from straightforward because it is very hard to find a robust characterisation across models of the configuration of shocks that drive the exchange rates and prices at any given point in time. The results are mostly insignificant, and in the case of import prices in Lithuania, even with the wrong sign. Moving to the local projections, we thus sought to explain inflation by using common euro area shocks to FX and (relative) monetary policy. This effort yielded some interesting outcomes. The magnitudes for FX (NEER) shocks, which are closer to the idea of ERPT, are generally bigger than in the literature in the long run for import prices, while they look generally smaller for HICP. For consumer prices, the results for Lithuania and Estonia are very much in line with Beirne and Bijsterbosch (2009). It is very difficult to find significant PERRs to consumer prices using common euro area FX shocks. Latvia has the wrong sign for FX shocks, and the magnitudes are much smaller as compared with the other two countries regarding reactions to relative monetary policy shocks.

Looking at the pass-thoughs, by applying several methods, we found that Latvia indeed seems to be an outlier most of the time. A possible explanation for this finding is the different exchange rate regime in Latvia, which had a fixed regime to SDR up until 2005 when it joined the ERM II. We also performed a check with data for Latvia from 2005 using only local projections. The results do not change much compared to our baseline for the PERR to FX shock, and the magnitude is just slightly bigger in the case of a relative monetary policy shock. In any case, the results are not significantly different from zero for consumer prices.

Lastly, the results for core HICP (Table 5) are smaller than the ones for HICP, both in the case of FX shocks and that of relative monetary policy, which highlights the importance of the pass-through of energy and food prices in these economies.

[Insert here Table 3-5] 


\section{Conclusions}

In this paper, we investigate the Exchange Rate Pass-Through (ERPT) to import and consumer prices in the three Baltic states. Initially, we look at the results from reduced form equations. It is far from a trivial exercise to capture ERPT, especially in the case of consumer prices. For import prices, it can of some guidance, coming from pricing equations. For consumer prices, a simple ERPT is unclear, due to the process of price aggregation. Then, making use of a Bayesian VAR with zero and sign restrictions, we analyse measures of shock-dependent ERPT. The strong assumption that the exchange rate is governed solely by exogenous shocks to itself has already been challenged in some theoretical contributions, but only recently applied in empirical measures of ERPTs aimed at having shock-dependent ERPTs. The possible underlying reasons for a shock-dependence of ERPT are many. For example, price setters may react differently to exchange rate movements triggered by different economic shocks. It is worth recalling that there is a huge modelling challenge in analysing shock dependence in a country-specific setup: Structural VARs exchange rate and monetary policy shocks, which are mostly common to the whole euro area and not entirely country specific in the considered time span, cannot be fully identified using data from only one country. For instance, even if the NEER is country-specific, due to the initial sample periods and differences in trade partners, most part is linked to the behaviour of the euro (the three Baltic states had for many years intermediate regimes linked to the euro and were into the ERM II before joining). For relative monetary policy, the reasoning is similar and the variable is actually only driven by decisions at the euro area level. This is the reason that we also provide a local projection exercise, with common euro area shocks identified instead in a euro area-specific Bayesian SVAR and then extrapolated and used as a regressors. These methods are not expected to deliver the same results and can be seen as different approaches to understanding trasmission of NEER variations to prices, based on different definitions (see Section 3). Our work thus finds a central place in an ongoing debate in the literature. As there is no consensus on how best to approach ERPT estimations, we decided to examine the entire spectrum to understand the link between NEER and prices in these countries, and why we should be careful with plain numbers.

We find that results from reduced form equations are in line with the literature while, in general, country-specific BVARs do not yield significant results. The magnitudes for common euro area exchange rate shocks in the local projections are generally bigger than in the literature in the long run for import prices (between 0.5 in case of Estonia and Lithuania, and 0.8 for Latvia). For consumer prices the 
magnitude is smaller, i.e. around 0.1 in the short run and 0.2 after four quarters. With respect to the pass-throughs, by applying several several methods, we found that Latvia seems to be an outlier most of the time. ${ }^{28}$ Lastly, the results for core HICP are smaller than those for HICP, both in the case of FX shocks and of relative monetary policy. The pass-through of energy and food prices in these economies is found to be quite relevant. Only in Estonia and in Lithuania can we see some influence of monetary policy shocks on service prices. We do not see any significant impact of FX shocks on the price components.

\footnotetext{
${ }^{28}$ We also performed a check with data for Latvia from 2005 only, due to the different exchange regime it had. This is feasible with a small $\mathrm{T}$ in a BVAR environment. The results do not change considerably compared to our baseline.
} 


\section{References}

[1] Bitans, M. 2004. Pass-Through of Exchange Rates to Domestic Prices in East European Countries and the Role of Economic Enviroment. Working Papers 2004/04, Latvijas Banka.

[2] Bijsterbosch, M.\& Beirne, J., 2009. Exchange Rate Pass-through in Central and Eastern European Member states. Working Paper Series 1120, European Central Bank.

[3] Campa, J. M. \& Goldberg, L. S., 2005. Exchange Rate Pass-Through into Import Prices. The Review of Economics and Statistics, pp. 679-690.

[4] Carriere-Swallow, Y. \& B. Gruss \& N. E. Magud \& F. Valencia, 2016. Monetary Policy Credibility and Exchange Rate Pass-Through. IMF Working Papers 16/240, International Monetary Fund.

[5] Coibon, O., Gorodnichenko, Y. \& Ulate, M., 2018. The Cyclical Sensitivity in Estimates of Potential Output. s.l., Brooking Papers on Economic Activity.

[6] Comunale, M. \& Kunovac, D., 2017. Exchange rate pass-through in the euro area. European Central Bank WP n.2003/2017.

[7] Comunale, M. \& Simola, H. 2018. The pass-through to consumer prices in CIS economies: The role of exchange rates, commodities and other common factors, Research in International Business and Finance, Elsevier, vol. 44(C), pages 186-217.

[8] Comunale, M. 2019. Shock dependence of exchange rate pass-through: a comparative analysis of BVARs and DSGEs. mimeo.

[9] Corsetti, G., Dedola, L. \& Leduc, S., 2008. High exchange-rate volatility and low pass-through. Journal of Monetary Economics, Volume 55, pp. 1113-1128.

[10] Dainauskas, J. \& Quittner, P., 2019. Why has exchange rate pass-through in the European Union changed over time?, mimeo.

[11] Dabusinskas, A. 2003. Exchange Rate Pass-Through to Estonian Prices, Bank of Estonia Working Paper No. 10.

[12] European Central Bank, 2019. Exchange rate pass-through in the euro area and EU countries. ECB Occasional Paper. forthcoming. 
[13] Forbes, K., Hjortsoe, I. \& Nenova, T., 2015. The shocks matter: improving our estimates of exchange rate pass-through. Discussion Papers 43, Monetary Policy Committee Unit, Bank of England.

[14] Forbes, K., Hjortsoe, I. \& Nenova, T., 2017. Shocks versus structure: explaining differences in exchange rate pass-through across countries and time. Bank of England Discussion Paper No.50.

[15] Forbes, K., Hjortsoe, I. \& Nenova, T., 2018. The shocks matter: improving our estimates of exchange rate pass-through. Journal of International Economics, Volume 115, pp. 255-275.

[16] Goldberg, P. K., \& Knetter, M. M. (1997). Goods Prices and Exchange Rates: What Have We Learned?, Journal of Economic Literature, 35, 12431272.

[17] Gopinath, G., 2015. The International Price System. National Bureau of Economic Research, Inc.

[18] Gorodnichenko, Y. \& B. Lee, 2017. A Note on Variance Decomposition with Local Projections, NBER Working Papers 23998, National Bureau of Economic Research, Inc.

[19] Krippner, L. 2016. Documentation for measures of monetary policy. New Zealand's central bank, mimeo.

[20] Jimborean, R., 2013. The Exchange Rate Pass-Through in the New EU Member states. Economic Systems, 2013, vol. 37, issue 2, 302-329

[21] Jorda O., 2005. Estimation and Inference of Impulse Responses by Local Projections. The American Economic Review, pp. 161-182.

[22] Leiva-Leon, D., Martinez-Martin, J. \& Ortega, E., 2018. Recent Movements in the Euro Exchange Rate and the Impact on Inflation in the Spanish Economy. Banco de Espańa Analytical Articles, $4-2018$.

[23] Maria-Dolores, R. 2009. Exchange Rate Pass-Through in Central and East European Countries. Eastern European Economics, Taylor \& Francis Journals, vol. 47(4), pages 42-61, July.

[24] Masso, J.\& Staehr, K., 2005. Inflation dynamics and nominal adjustment in the Baltic states, Research in International Business and Finance, Elsevier, vol. 19(2), pages 281-303, June.

[25] Montes-Galdon, C., Osbat, C. \& Tagliabracci, A. 2019 . Shock-dependence in Exchange Rate PassThrough, mimeo. 
[26] Riksbank, 2016. The impact of the exchange rate on inflation. Riksbank Monetary Policy Report Article, December 2016.

[27] Shambaugh, J., 2008. A new look at pass-through. Journal of International Money and Finance, 6, Volume 27, pp. 560-591.

[28] Saiki, A. 2011.Exchange Rate Pass-Through and Monetary Integration in the Euro Area, DNB Working Papers 308, Netherlands Central Bank, Research Department.

[29] Staehr, K., 2016. Exchange Rate Policies in the Baltic states: From Extreme Inflation to Euro Membership, CESifo Forum, ifo Institute - Leibniz Institute for Economic Research at the University of Munich, vol. 16(4), pages 09-18, January. 


\section{Annex}

Table 1: a summary of results from the literature

\begin{tabular}{|c|c|c|c|c|c|}
\hline Study & Sample period & Methodology & Country & $\begin{array}{l}\text { ERPT to import } \\
\text { prices }\end{array}$ & ERPT to consumer prices \\
\hline & 1998M1-2003M6 & & $\mathrm{EE}$ & & $0.21(1 Q)-0.34(4 Q, 8 Q)$ \\
\hline \multirow[t]{2}{*}{ Bitans (2004) } & 1998M1-2003M6 & VAR with Cholesky & LV & & $0.13(1 Q)-0.26(4 Q, 8 Q)$ \\
\hline & 1998M1-2003M6 & & LT & & $0.22(1 Q)-0.28(4 Q)-0.398 Q)$ \\
\hline Dabusinskas (2003) & 1995 Q1-2003 Q1 & Single equation ARDL - SUR & $\mathrm{EE}$ & 0.4 (long-run) & not significant \\
\hline Maria-Dolores (2009) & 2000m1-2006m12 & $\begin{array}{l}\text { Single equation methods (with and } \\
\text { without Error Correction Models) }\end{array}$ & LV & $\begin{array}{r}0.9 \text { (short-run) }-0.76 \\
\text { (long-run) }\end{array}$ & between 0.24 and 0.36 \\
\hline \multirow[t]{3}{*}{ Beirne and Bijsterbosch (2009) } & 1998M1-2008M4 & & $\mathrm{EE}$ & & $\begin{array}{r}0.06(2 \mathrm{Q})-0.16(4 \mathrm{Q})-0.57(8 \mathrm{Q})- \\
0.92 \text { (long-run) }\end{array}$ \\
\hline & 1996M1-2008M4 & Cointeg rated VAR - VECM & LV & & $\begin{array}{r}0.36(2 \mathrm{Q})-0.44(4 \mathrm{Q})-0.51(8 \mathrm{Q})- \\
0.97 \text { (long-run) }\end{array}$ \\
\hline & 1998M1-2008M4 & & LT & & $\begin{array}{r}0.15(2 Q)-0.21(4 Q)-0.46(8 Q)- \\
0.44 \text { (long-run) }\end{array}$ \\
\hline \multirow[t]{3}{*}{ Jimborean (2013) } & 1996Q1 - 2010Q2 & $\begin{array}{l}\text { Dynamic (panel GMM and) country-by- } \\
\text { country }\end{array}$ & EE & $1.07(1 \mathrm{Q})$ & $0.33(1 \mathrm{Q})$ \\
\hline & 1996Q1 - 2010Q2 & & LV & $0.56(1 Q)$ & 0.05 ( $1 \mathrm{Q}$, not significant) \\
\hline & 1996Q1 - 2010Q2 & & LT & $0.47(1 Q)$ & 0.07 ( $1 \mathrm{Q}$, not significant) \\
\hline \multirow[t]{3}{*}{ Carriere-Swallowet al. (2016) } & 2000M1-2015M12 & & EE & & $0.48(4 Q)-0.22(8 Q)$ \\
\hline & 2000M1-2015M12 & $\begin{array}{l}\text { Reduced-form specification - Local } \\
\text { projections }\end{array}$ & LV & & $0.26(4 Q)-0.68(8 Q)$ \\
\hline & 2000M1-2015M12 & & LT & & $0.39(4 Q)-0.64(8 Q)$ \\
\hline
\end{tabular}


Table 2: identification scheme a la Comunale and Kunovac (2017)

\begin{tabular}{|c|c|c|c|c|c|c|}
\hline \multicolumn{7}{|l|}{ Short run restrictions } \\
\hline & GDP & HICP & IR & FX & IP & EXP \\
\hline Domestic supply shock (AS) & -1 & 1 & * & * & * & 0 \\
\hline Domestic demand Shock (AD) & 1 & 1 & 1 & -1 & * & 0 \\
\hline Foreign demand shock (GD) & 1 & 1 & * & * & * & 1 \\
\hline Exogenous exchange rate shock ( $\mathrm{FX}$ ) & * & 1 & * & 1 & 1 & * \\
\hline Relative monetary policy (MP) & 1 & 1 & -1 & 1 & $*$ & * \\
\hline Foreign supply shock (GS) & -1 & 1 & * & * & * & 1 \\
\hline & & & & & & \\
\hline \multicolumn{7}{|l|}{ Long run restrictions } \\
\hline & GDP & HICP & IR & FX & IP & EXP \\
\hline Domestic supply shock (AS) & * & * & * & * & * & * \\
\hline Domestic demand Shock (AD) & 0 & * & * & * & * & * \\
\hline Foreign demand shock (GD) & 0 & * & * & * & * & * \\
\hline Exogenous exchange rate shock (FX) & 0 & * & * & * & * & * \\
\hline Relative monetary policy (MP) & 0 & * & * & * & * & * \\
\hline Foreign supply shock (GS) & * & * & * & * & $*$ & * \\
\hline
\end{tabular}

Note: Lag length: 2. Re-normalised so that all inflationary. Impulses responses are "normalized" in a way that median response of fourth variable (exchange rate) to every shock is equal to 1 at the horizon zero.

GDP is real GDP, HICP is consumer price inflation, IR is the shadow rate, FX is the NEER, IP is import price and EXP stands for competitors export prices. 
Table 3: summary of our results for ERPT with reduced form equations

\begin{tabular}{c|c|c|c|c|} 
Study & Methodology & Country & $\begin{array}{c}\text { ERPT to import } \\
\text { prices }\end{array}$ & $\begin{array}{c}\text { ERPT to consumer } \\
\text { prices }\end{array}$ \\
\hline \multirow{4}{*}{ Reduced form } & & EE & - & $0.33(1 Q), 0.85(4 Q)$ \\
& \multirow{3}{*}{ Bivariate } & LV & - & $0.09(1 Q), 0.29(4 Q)$ \\
& & LT & - & $0.29(1 Q), 1.51(4 Q)$ \\
\cline { 2 - 5 } & \multirow{3}{*}{ Phillips } & EE & - & $0.00(1 Q), 0.2(4 Q)$ \\
& & LV & - & $0.61(1 Q), 1.85(4 Q)$ \\
& & LT & - & $0.00(1 Q), 0.25(4 Q)$ \\
\hline
\end{tabular}

Table 4: summary of our results for ERPT/PERR

\begin{tabular}{|c|c|c|c|c|}
\hline Study & Methodology & Country & $\begin{array}{l}\text { ERPT to import } \\
\text { prices }\end{array}$ & $\begin{array}{l}\text { ERPT to consumer } \\
\text { prices }\end{array}$ \\
\hline \multirow{9}{*}{$\begin{array}{l}\text { Country-specific } \\
\text { BVARs }\end{array}$} & \multirow{3}{*}{ PERR to $F X$ shock } & $\mathrm{EE}$ & $0.47(1 Q), 0.32(4 Q)$ & $0.22(1 Q), 0.28(4 Q)$ \\
\hline & & LV & $1.08(1 Q), 0.83(4 Q)$ & $0.32(1 Q), 0.59(4 Q)$ \\
\hline & & LT & $1.35(1 Q), 0.62(4 Q)$ & $0.28(1 Q), 0.36(4 Q)$ \\
\hline & \multirow{3}{*}{ PERR to relative MP shock } & $\mathrm{EE}$ & $0.36(1 \mathrm{Q}), 0.30(4 \mathrm{Q})$ & $0.20(1 \mathrm{Q}), 0.26(4 \mathrm{Q})$ \\
\hline & & LV & $0.17(1 Q), 0.16(4 Q)$ & $0.38(1 Q), 0.67(4 Q)$ \\
\hline & & LT & $-0.35(1 Q),-0.20(4 Q)$ & $0.20(1 Q), 0.36(4 Q)$ \\
\hline & \multirow{3}{*}{ TV-PERR } & $\mathrm{EE}$ & $0.16(0.16)$ & $0.13(0.11)$ \\
\hline & & LV & $0.43(0.38)$ & $0.37(0.17)$ \\
\hline & & LT & $0.10(0.15)$ & $0.07(0.06)$ \\
\hline \multirow{6}{*}{ Local projections } & \multirow{3}{*}{$\begin{array}{c}\text { FX shocks from euro area } \\
\text { BVARs }\end{array}$} & $\mathrm{EE}$ & $0.21(1 Q), 0.51(4 Q)$ & $0.12(1 Q), 0.16(4 Q)$ \\
\hline & & LV & $0.49(1 Q), 0.85(4 Q)$ & $-0.10(1 Q),-0.24(4 Q)$ \\
\hline & & LT & $0.17(1 Q), 0.58(4 Q)$ & $0.09(1 Q), 0.21(4 Q)$ \\
\hline & \multirow{3}{*}{$\begin{array}{l}\text { Relative monetary policy shocks } \\
\text { from euro area BVARs }\end{array}$} & $\mathrm{EE}$ & $0.31(1 Q), 0.48(4 Q)$ & $0.36(1 Q), 0.45(4 Q)$ \\
\hline & & LV & $0.70(1 Q), 1.24(4 Q)$ & $0.04(1 Q), 0.01(4 Q)$ \\
\hline & & LT & $1.14(1 \mathrm{Q}), 1.70(4 \mathrm{Q})$ & $0.10(1 Q), 0.20(4 Q)$ \\
\hline
\end{tabular}

Note: TV-PERR based on the results for 2017Q4 and average TV-PERR for 2017 in brackets.

Table 5: summary of our results for ERPT/PERR for core HICP (HICPX)

\begin{tabular}{|c|c|c|c|c|}
\hline Study & Methodology & Country & ERPT to HICP & ERPT to core HICP \\
\hline \multirow{6}{*}{$\begin{array}{l}\text { Local } \\
\text { projections }\end{array}$} & \multirow{3}{*}{ FX shocks from euro area BVARs } & EE & $0.12(1 \mathrm{Q}), 0.16(4 \mathrm{Q})$ & $0.04(1 \mathrm{Q}), 0.04(4 \mathrm{Q})$ \\
\hline & & LV & $-0.10(1 Q),-0.24(4 Q)$ & $0.05(1 \mathrm{Q}), 0.05(4 \mathrm{Q})$ \\
\hline & & LT & $0.09(1 Q), 0.21(4 Q)$ & $0.01(1 Q), 0.11(4 Q)$ \\
\hline & \multirow{3}{*}{$\begin{array}{l}\text { Relative monetary policy shocks } \\
\text { from euro area BVARs }\end{array}$} & $\mathrm{EE}$ & $0.36(1 \mathrm{Q}), 0.45(4 \mathrm{Q})$ & $0.07(1 Q), 0.00(4 Q)$ \\
\hline & & LV & $0.04(1 Q), 0.01(4 Q)$ & $0.02(1 Q), 0.09(4 Q)$ \\
\hline & & LT & $0.10(1 \mathrm{Q}), 0.20(4 \mathrm{Q})$ & $0.00(1 \mathrm{Q}), 0.00(4 \mathrm{Q})$ \\
\hline
\end{tabular}


Fig.1 Results from reduced form: Estonia
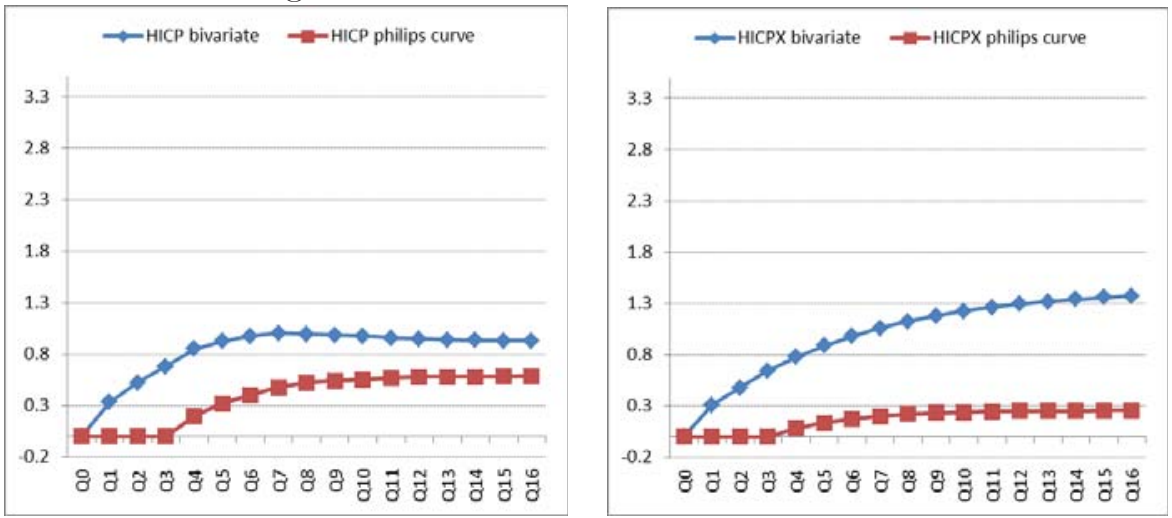

Fig.2 Results from reduced form: Latvia
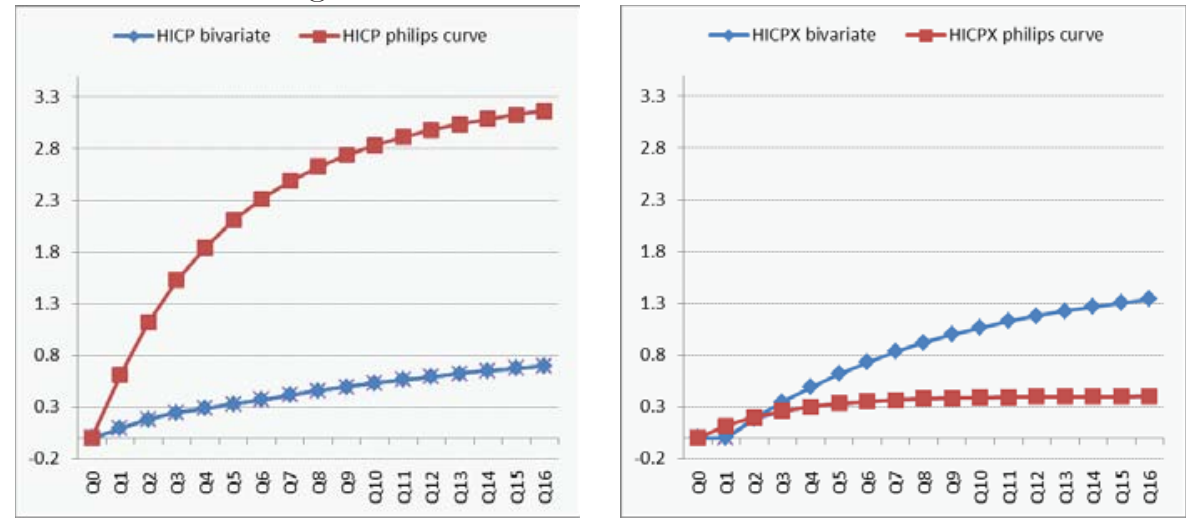

Fig.3 Results from reduced form: Lithuania
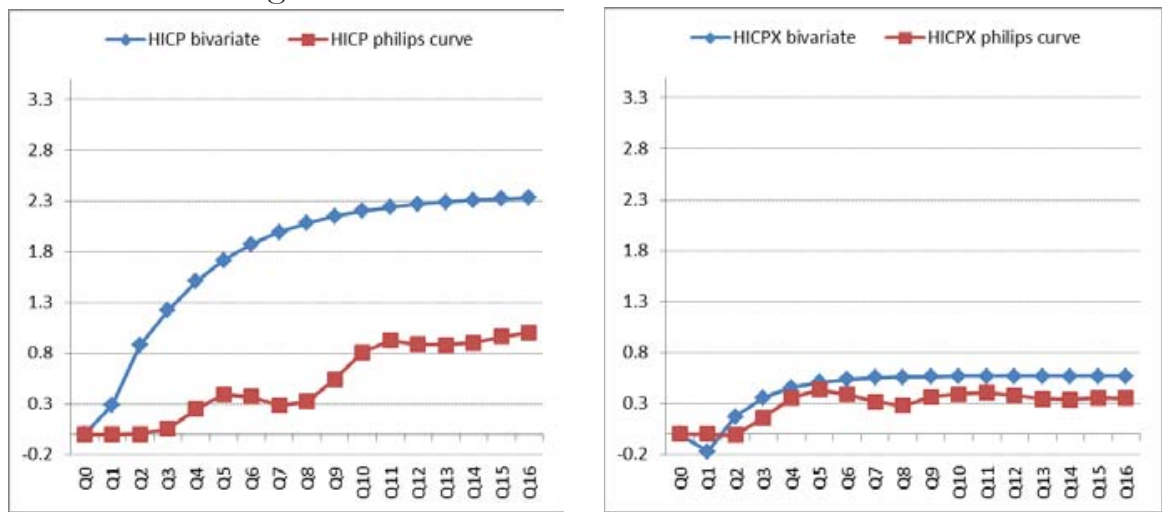
Fig.4 Results HICP and IP PERR to exogenous exchange rate and relative monetary policy shocks:

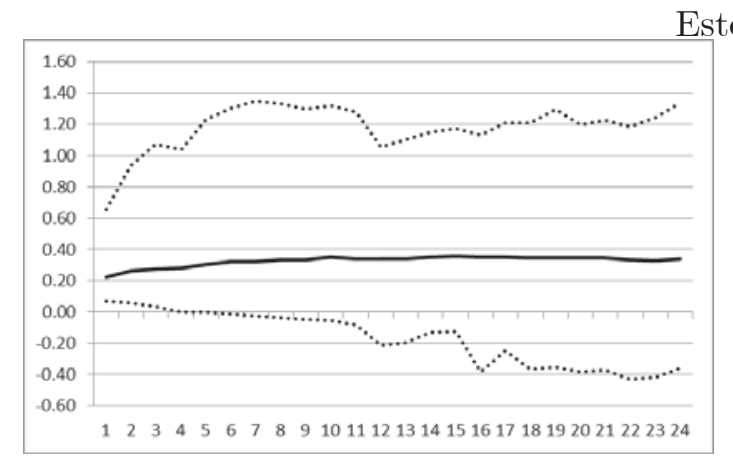

Estonia
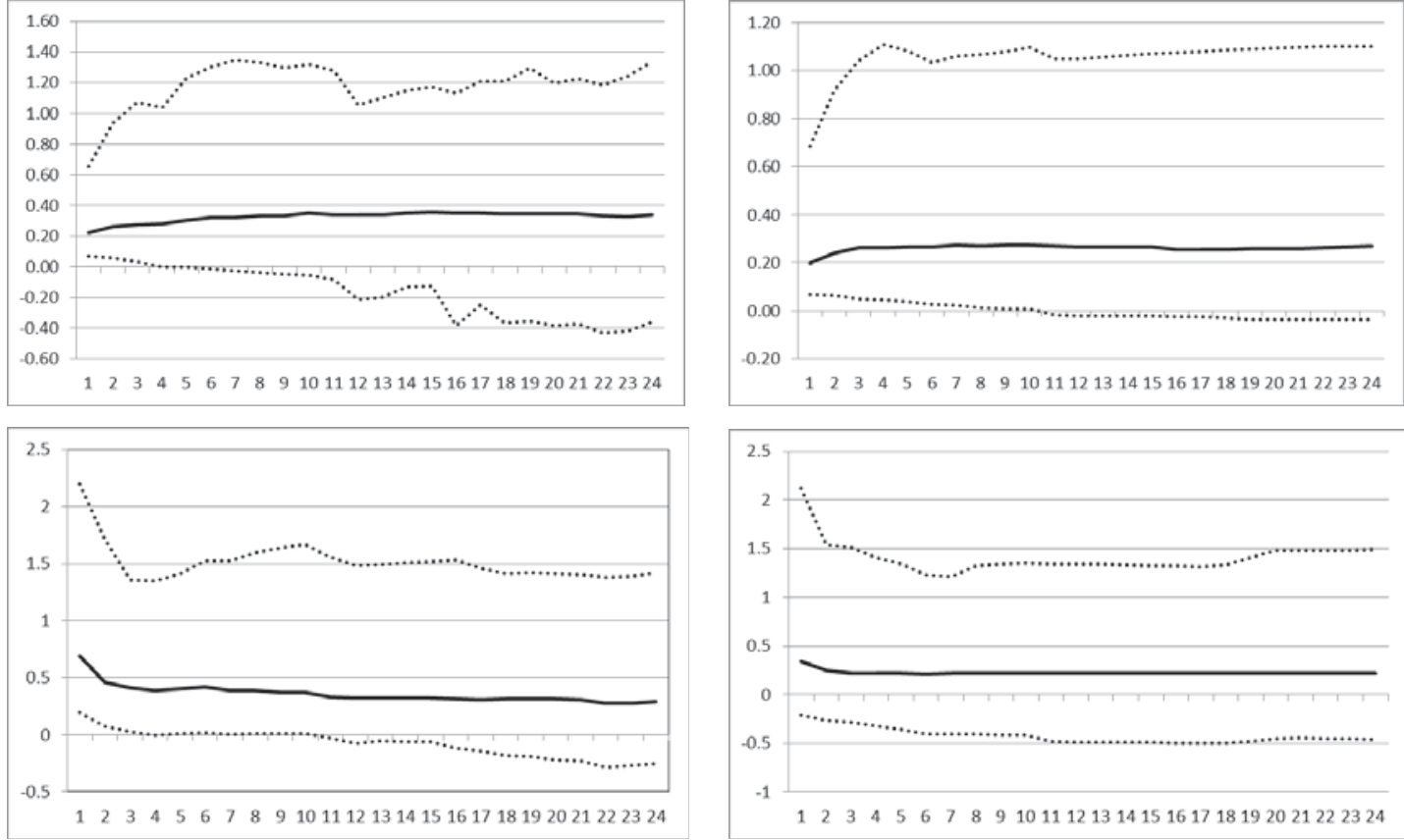

Note: FX (LHS) and relative MP shock (RHS). To HICP in the first row and to IP in the second row.

Fig.5 Results HICP and IP PERR to exogenous exchange rate and relative monetary policy shocks:

Latvia
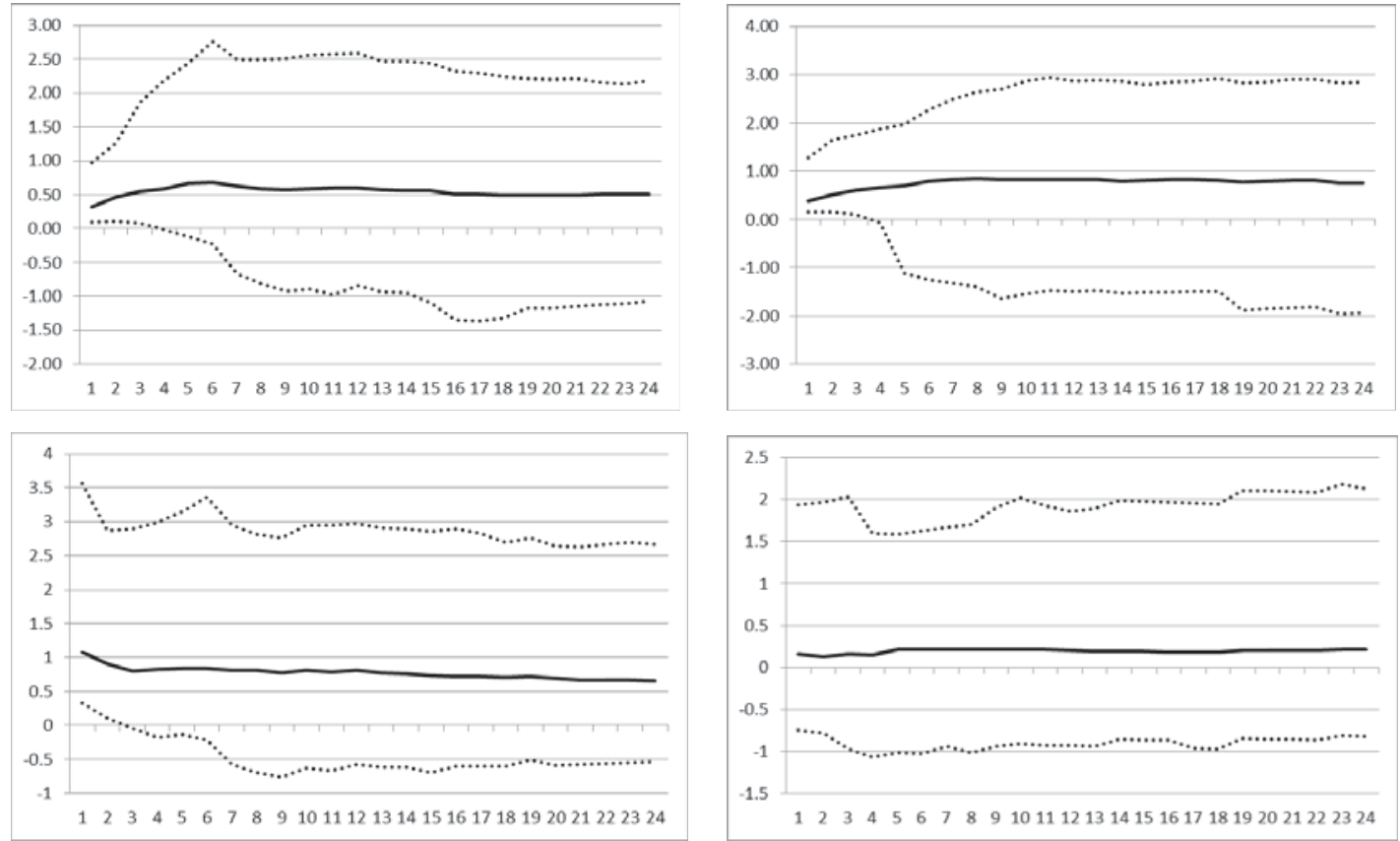

Note: FX (LHS) and relative MP shock (RHS). To HICP in the first row and to IP in the second row. 
Fig.6 Results HICP and IP PERR to exogenous exchange rate and relative monetary policy shocks:

Lithuania
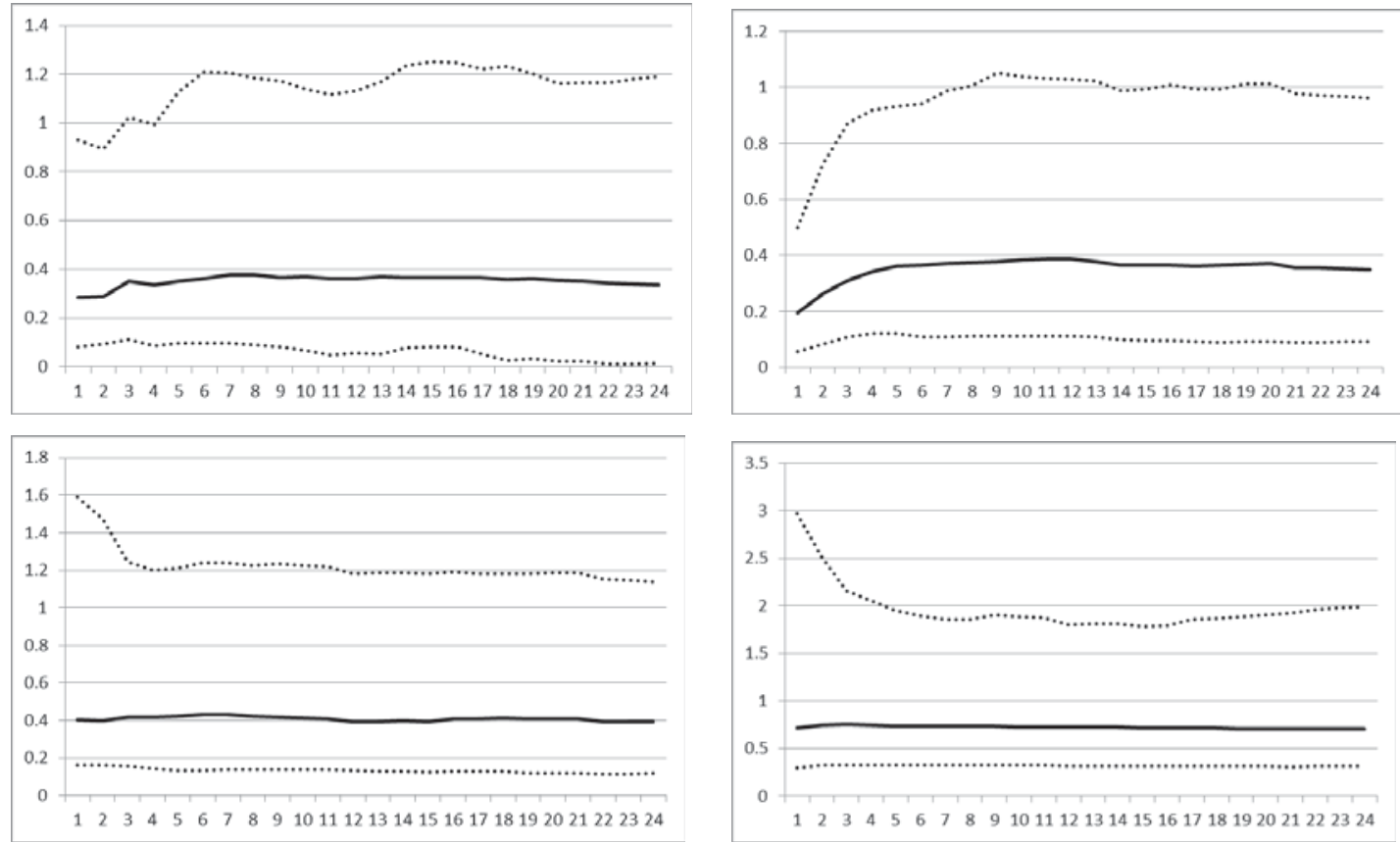

Note: FX (LHS) and relative MP shock (RHS). To HICP in the first row and to IP in the second row. 
Fig.7 Results HICP and IP TV-PERR: Estonia
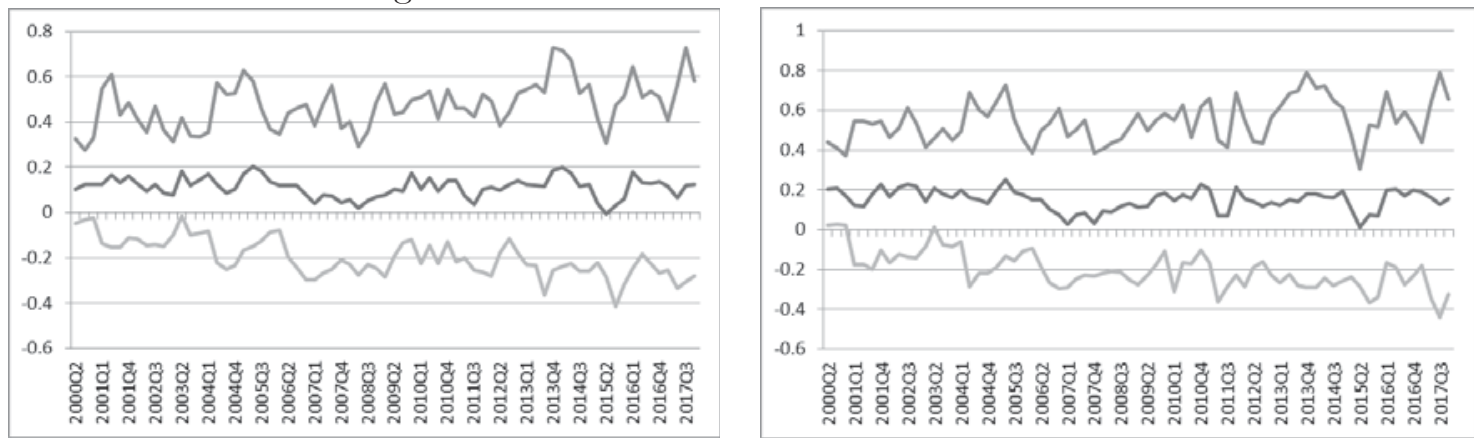

Note: To HICP in the LHS and to IP in the RHS.

Fig.8 Results HICP and IP TV-PERR: Latvia
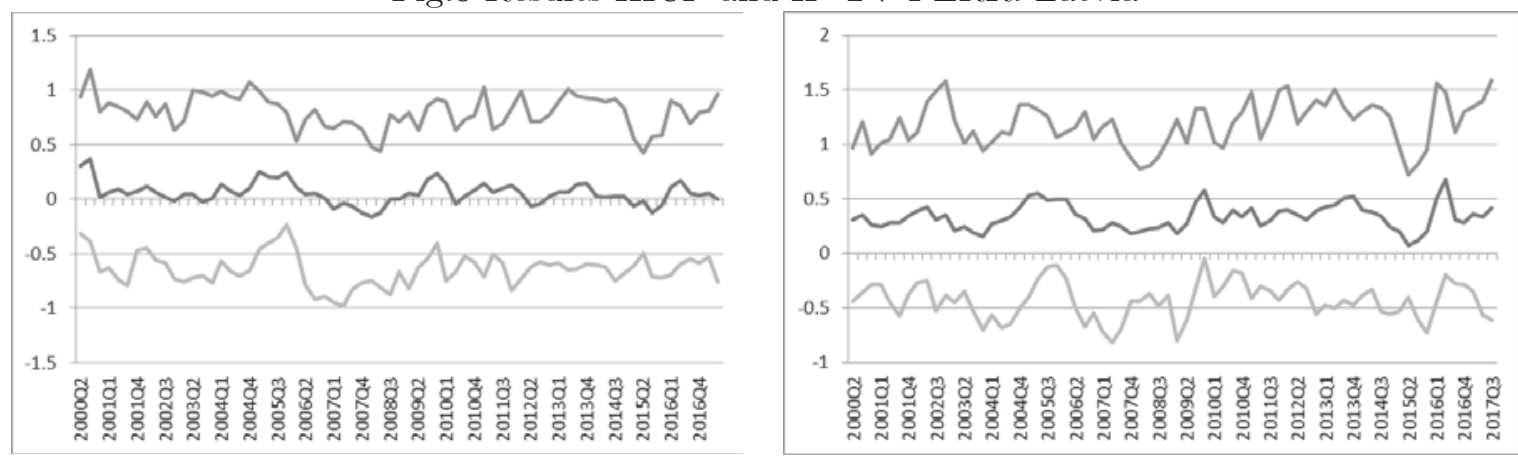

Note: To HICP in the LHS and to IP in the RHS.

Fig.9 Results HICP and IP TV-PERR: Lithuania
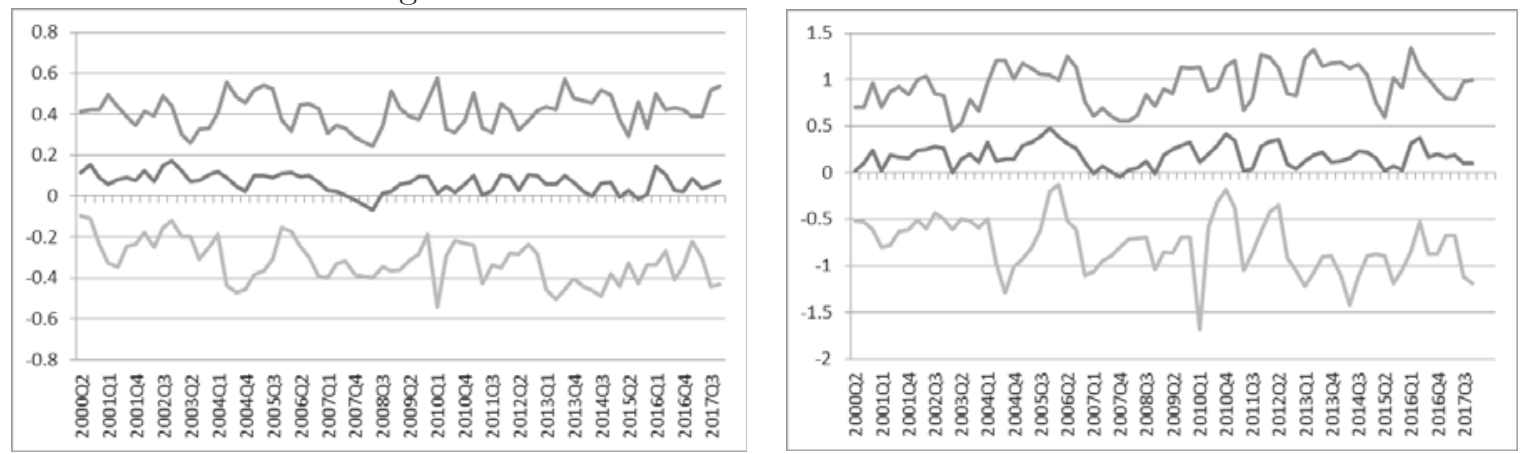

Note: To HICP in the LHS and to IP in the RHS. 
Fig.10 Results for consumer prices with local projections: Estonia
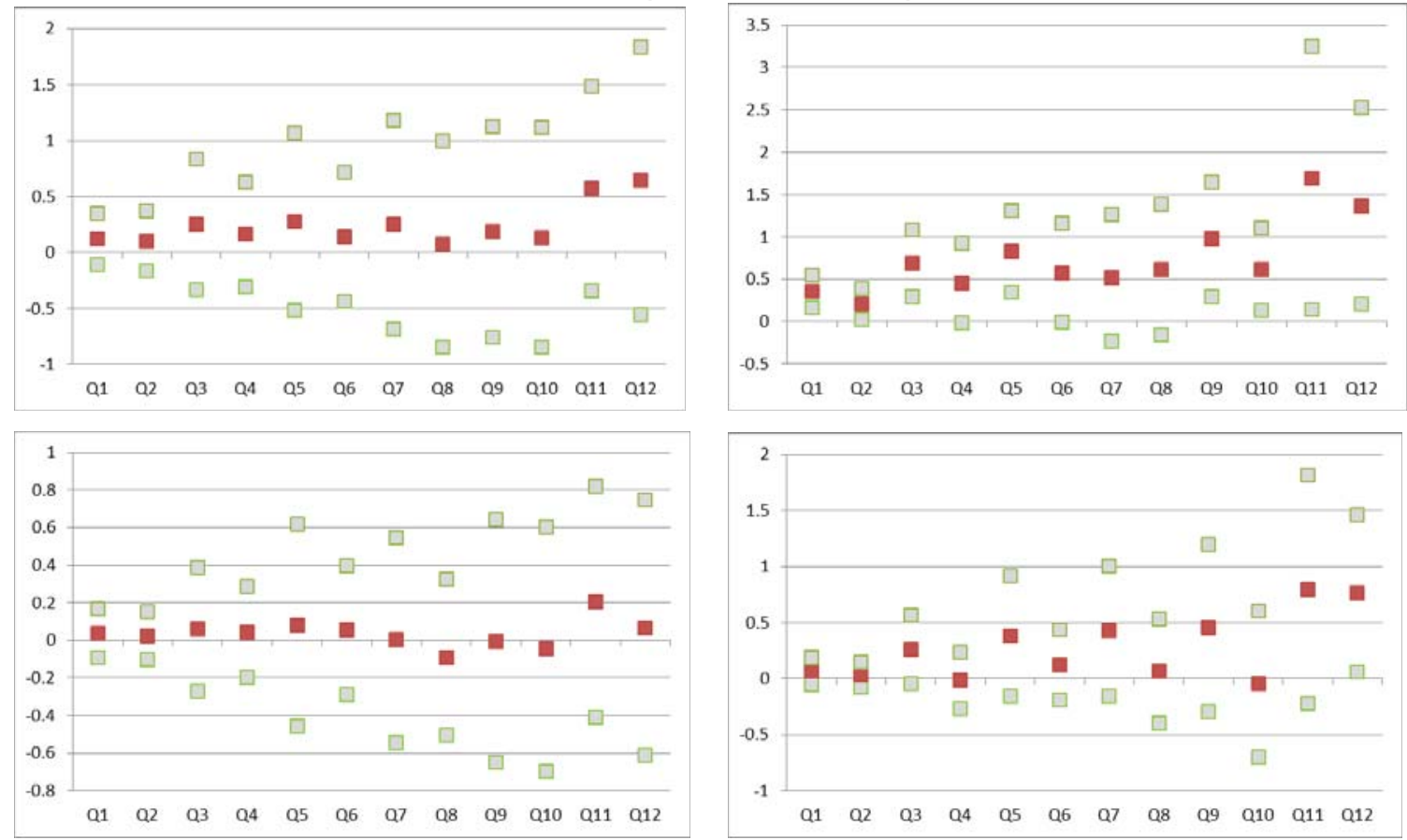

Note: top row LHS: HICP FX shock, top row RHS: HICP relative MP shock.

Then bottom row LHS: HICPX FX shock, bottom row RHS: HICPX relative MP shock.

Fig.11 Results for consumer prices with local projections: Latvia
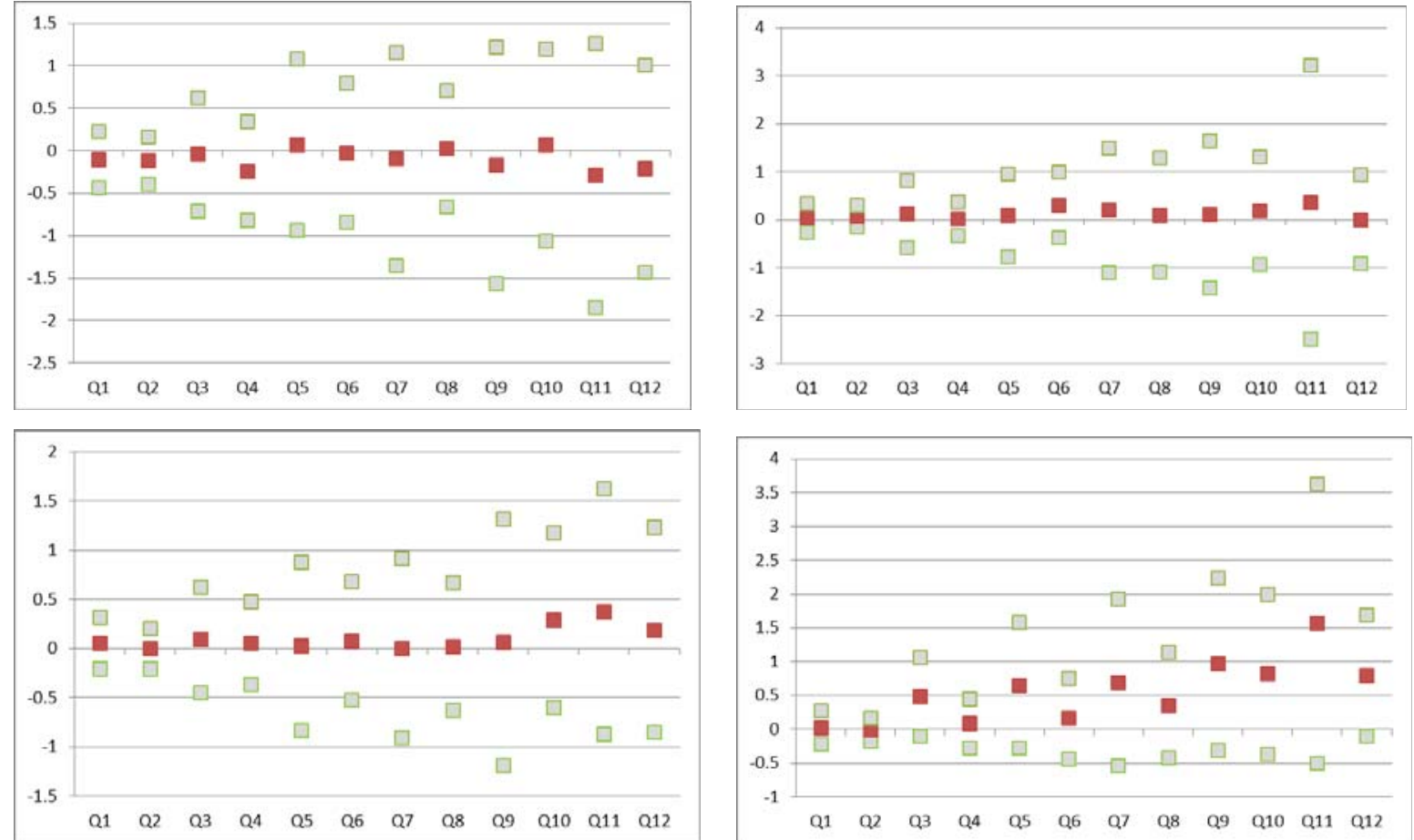

Note: top row LHS: HICP FX shock, top row RHS: HICP relative MP shock.

Then bottom row LHS: HICPX FX shock, bottom row RHS: HICPX relative MP shock. 
Fig.12 Results for consumer prices with local projections: Lithuania
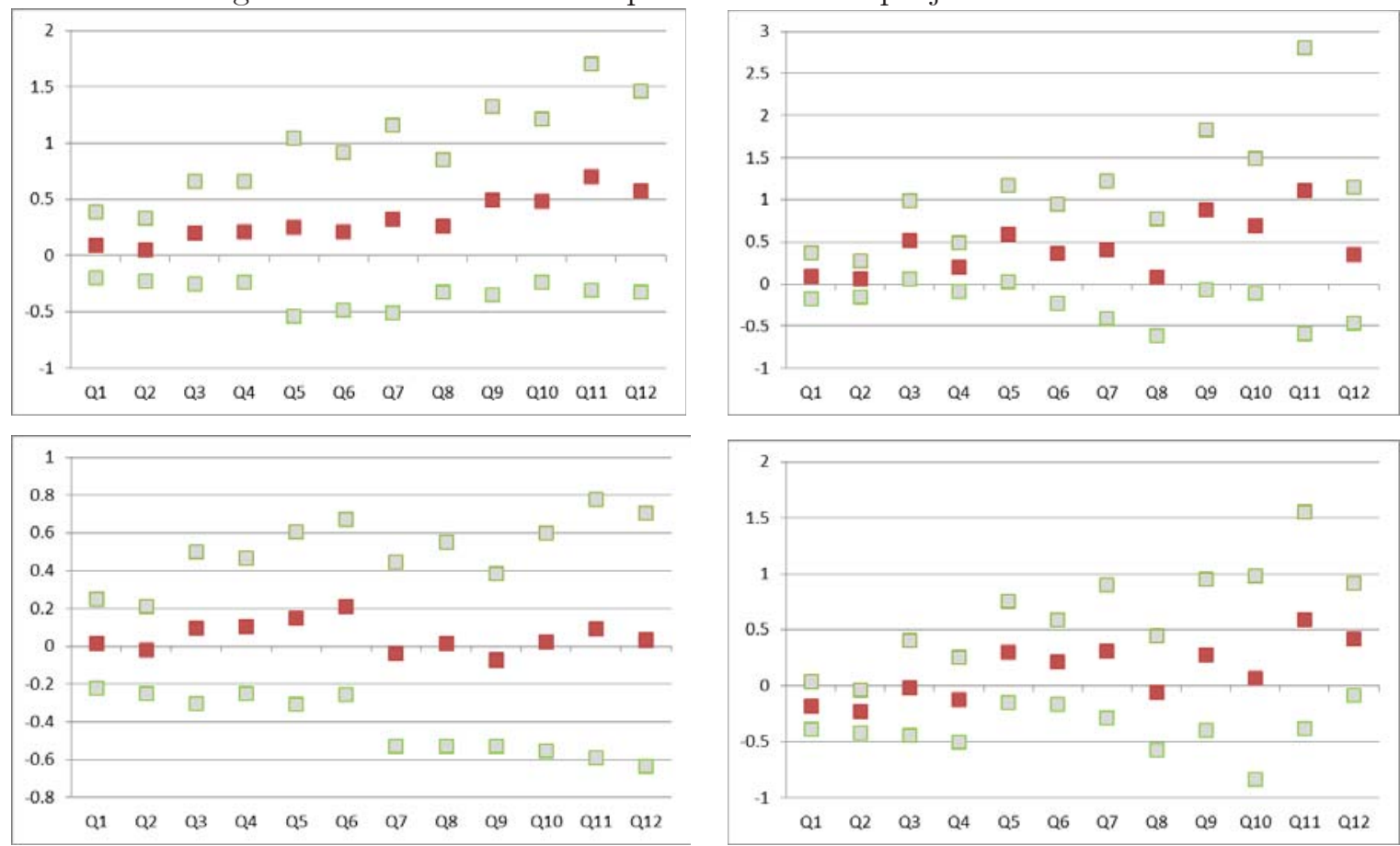

Note: top row LHS: HICP FX shock, top row RHS: HICP relative MP shock.

Then bottom row LHS: HICPX FX shock, bottom row RHS: HICPX relative MP shock. 
Fig.13 Results for import prices with local projections: Estonia
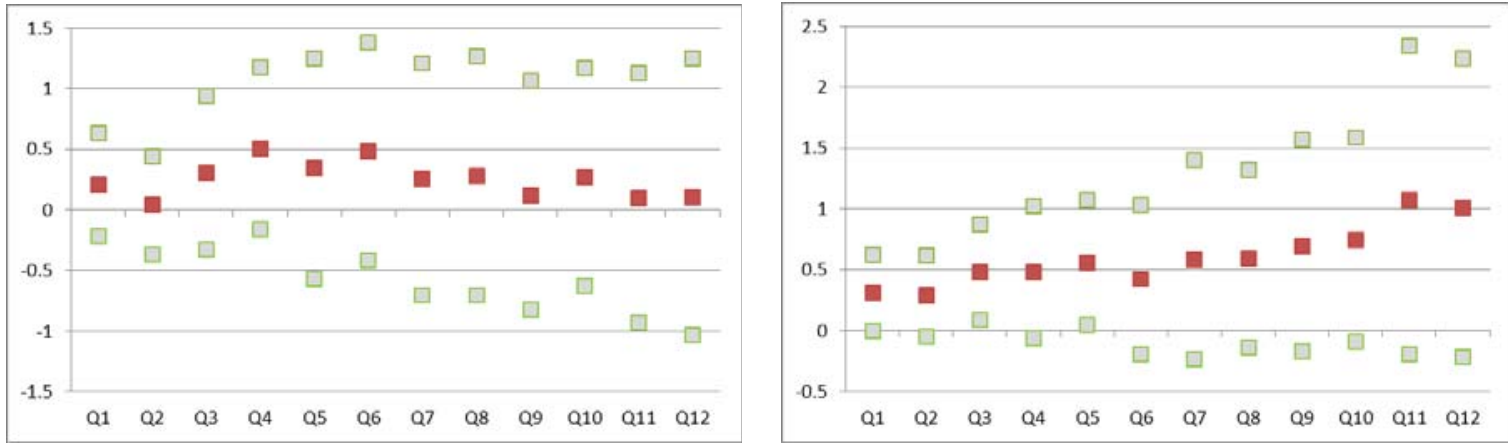

Note: LHS: IP FX shock, RHS: IP relative MP shock.

Fig.14 Results for import prices with local projections: Latvia
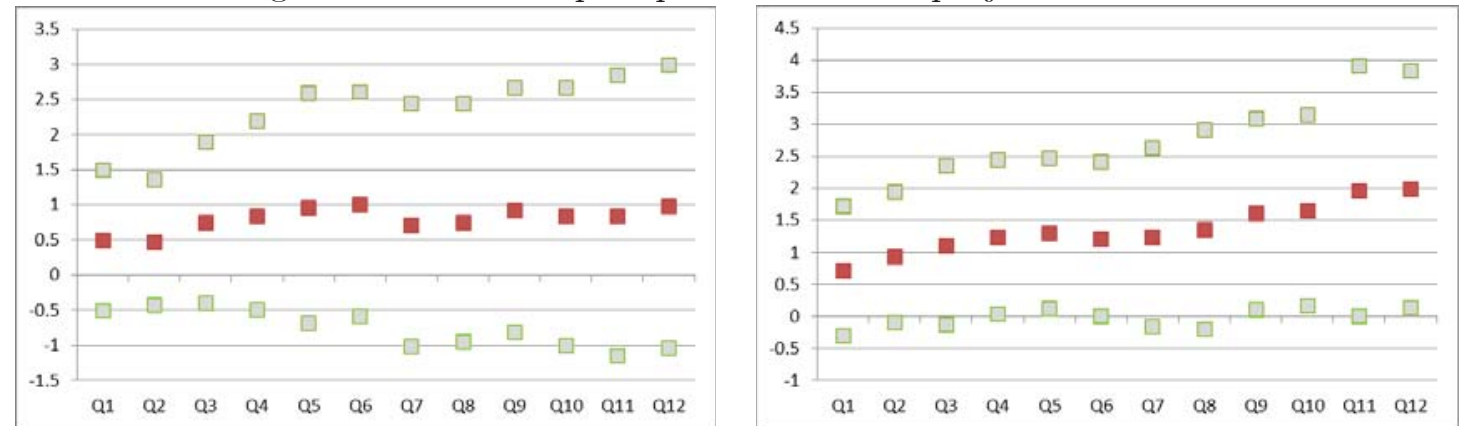

Note: LHS: IP FX shock, RHS: IP relative MP shock.

Fig.15 Results for import prices with local projections: Lithuania
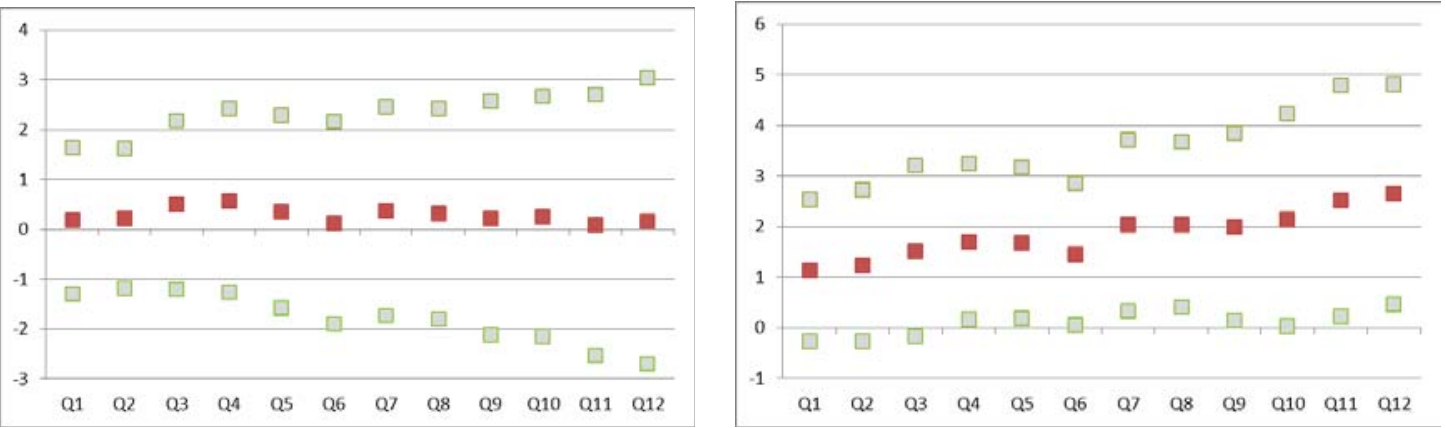

Note: LHS: IP FX shock, RHS: IP relative MP shock. 


\section{Appendix}

Fig. A1: NEER historical decomposition

(a) Estonia

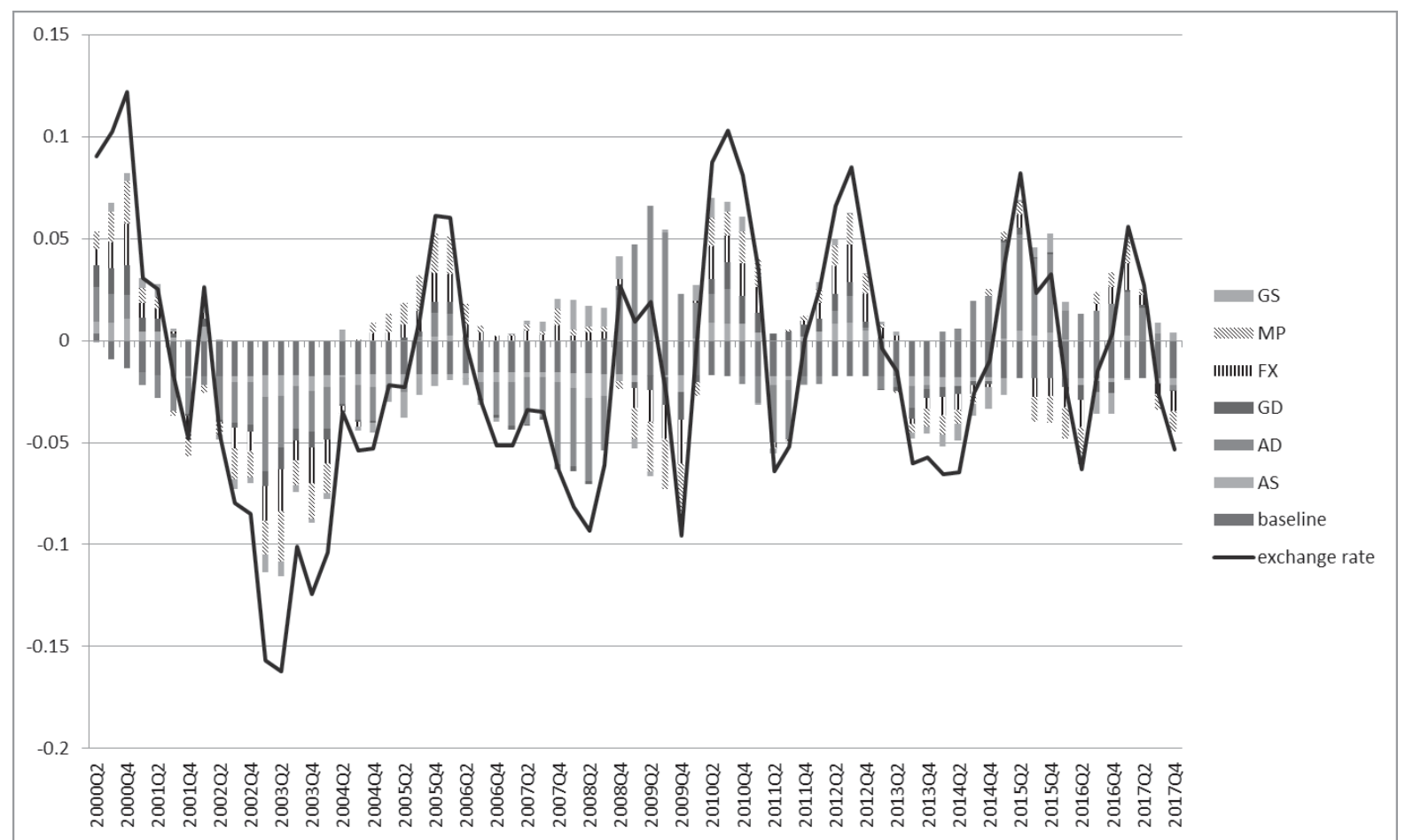

Note: GS is global/foreign supply, MP is the relative monetary policy, FX is the NEER, GD is the global/foreign demand, $\mathrm{AD}$ is the domestic demand, $\mathrm{AS}$ is the domestic supply. 
(b) Latvia

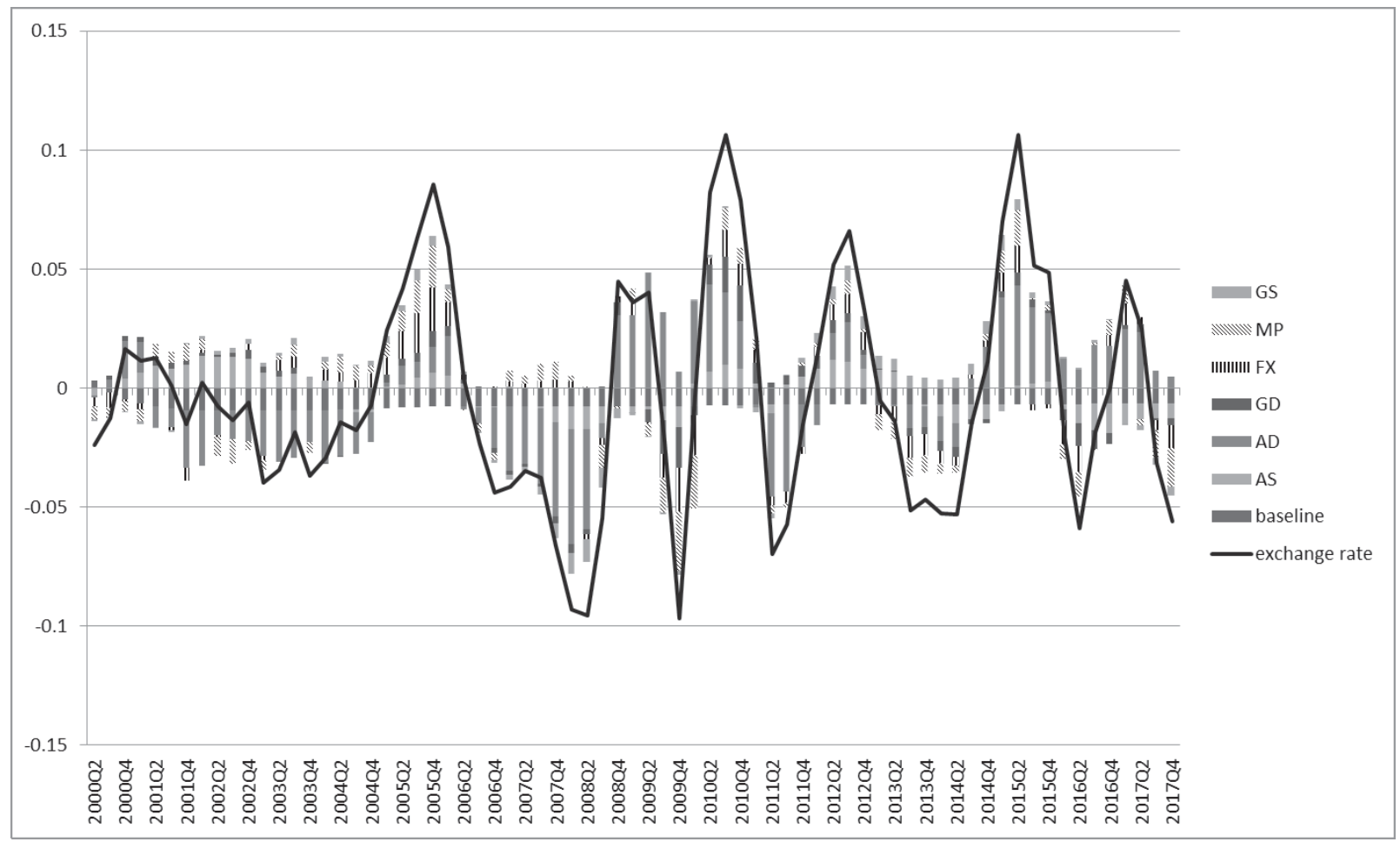

Note: GS is global/foreign supply, MP is the relative monetary policy, FX is the NEER, GD is the global/foreign demand, AD is the domestic demand, AS is the domestic supply. 
(c) Lithuania

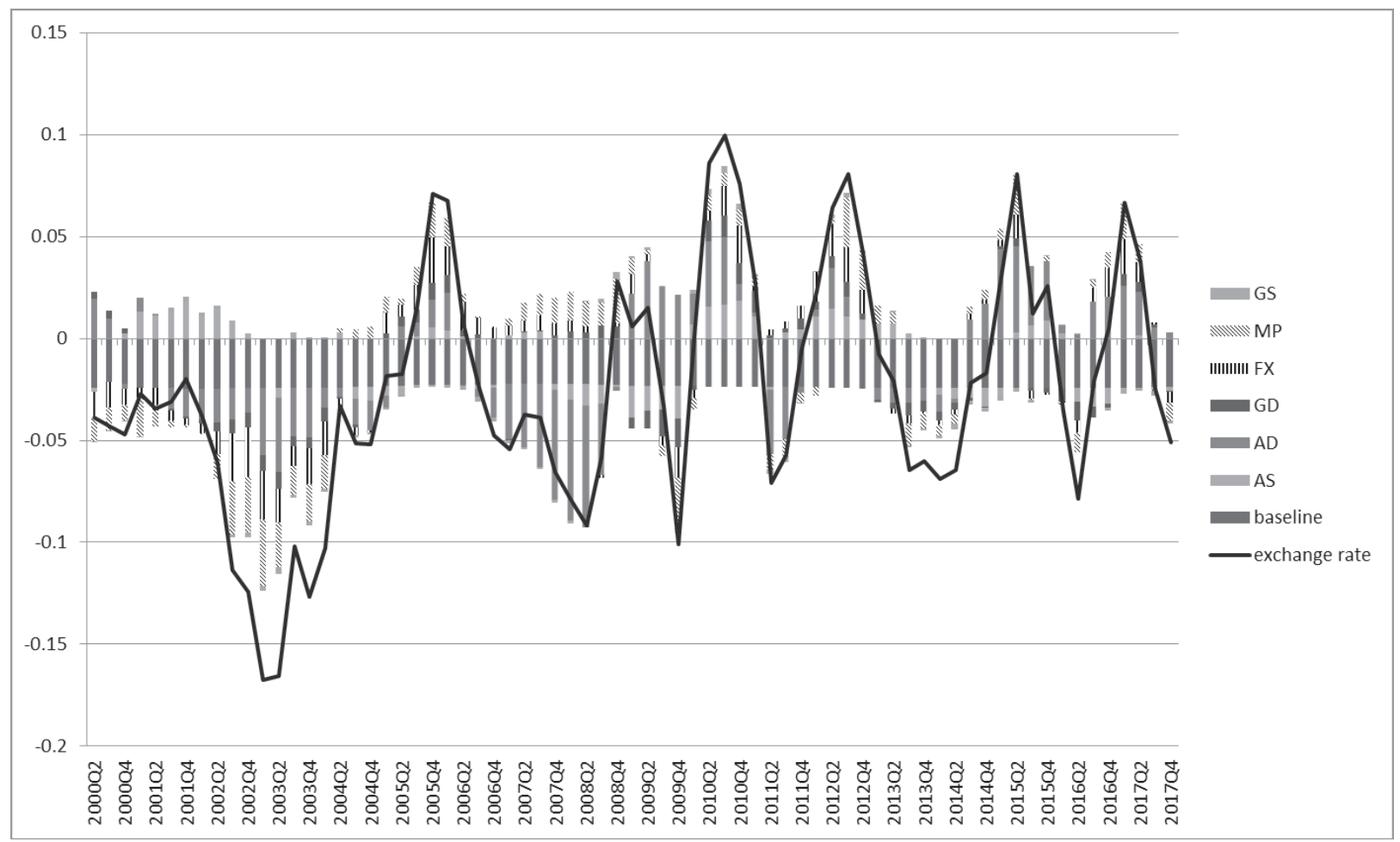

Note: GS is global/foreign supply, MP is the relative monetary policy, FX is the NEER, GD is the global/foreign demand, $\mathrm{AD}$ is the domestic demand, $\mathrm{AS}$ is the domestic supply. 